\title{
Next-Generation Vaccines Based on Bacille Calmette-Guérin
}

\section{Natalie E. Nieuwenhuizen and Stefan H. E. Kaufmann*}

Max Planck Institute for Infection Biology, Berlin, Germany

Tuberculosis (TB), caused by the intracellular bacterium Mycobacterium tuberculosis (Mtb), remains a major health threat. A live, attenuated mycobacterium known as Bacille Calmette-Guérin (BCG), derived from the causative agent of cattle TB, Mycobacterium bovis, has been in clinical use as a vaccine for 90 years. The current incidence of TB demonstrates that BCG fails to protect sufficiently against pulmonary TB, the major disease manifestation and source of dissemination. The protective efficacy of BCG is on average $50 \%$ but varies substantially with geographical location and is poorer in those with previous exposure to mycobacteria. BCG can also cause adverse reactions in immunocompromised individuals. However, BCG has contributed to reduced infant TB mortality by protecting against extrapulmonary TB. In addition, BCG has been associated with reduced general childhood mortality by stimulating immune responses. In order to improve the efficacy of BCG, two major strategies have been employed. The first involves the development of recombinant live mycobacterial vaccines with improved efficacy and safety. The second strategy is to boost BCG with subunit vaccines containing Mtb antigens. This article reviews recombinant BCG strains that have been tested against TB in animal models. This includes BCG strains that have been engineered to induce increased immune responses by the insertion of genes for Mtb antigens, mammalian cytokines, or host resistance factors, the insertion of bacterial toxin-derived adjuvants, and the manipulation of bacterial genes in order to increase antigen presentation and immune activation. Subunit vaccines for boosting BCG are also briefly discussed.

Keywords: tuberculosis, Mycobacterium bovis bacille Calmette-Guérin, vaccine, recombinant Mycobacterium bovis bacille Calmette-Guérin, subunit vaccine, mycobacteria

\section{INTRODUCTION}

The bacterium Mycobacterium tuberculosis (Mtb) remains one of the most difficult pathogens to control, and caused 10.4 million recorded cases of tuberculosis (TB) and 1.7 million recorded deaths in 2016 (1). Just under a quarter of the world's population is estimated to be latently infected with Mtb, with the highest prevalence in Africa and Asia (2). The risk of developing active disease for those with latent TB infection (LTBI) is greatest within the first 2 years and approximately $10 \%$

\footnotetext{
Abbreviations: Ag85B, antigen 85B; BCG, Mycobacterium bovis bacille Calmette-Guérin; CFP-10, culture filtrate protein-10; CT, cholera toxin; DCs, dendritic cells; ESAT-6, early secretory antigenic target-6; ESX-1, ESAT-6 secretion system 1; IL, interleukin; LC3, microtubule-associated protein light chain 3; LLO, listeriolysin O; LT, Escherichia coli heat labile toxin; LTBI, latent TB infection; MCP-3, monocyte chemotactic protein 3; MDR, multi-drug resistant; Mtb, Mycobacterium tuberculosis; NK, natural killer; NOX2, NADPH oxidase; Pfo, perfringolysin O; rBCG, recombinant BCG; RD(1-16), region of difference (1-16); ROS, reactive oxygen species; $S C I D$, severe combined immunodeficiency; $\mathrm{TB}$, tuberculosis; $\mathrm{T}_{\mathrm{CM}}$, central memory $\mathrm{T} ; \mathrm{T}_{\mathrm{EM}}$, effector memory $\mathrm{T}$; Thl, T helper cell type 1; $\mathrm{T}_{\mathrm{RM}}$, resident memory $\mathrm{T} ; \mathrm{XDR}$, extremely drug resistant.
} 
over a lifetime, or 5-10\% per year in HIV infected individuals (3). Treatment with drugs requires 6-9 months of antibiotics, and not only multi-drug resistant (MDR) strains but also extremely drugresistant (XDR) strains continue to emerge, leading to extended drug treatment regimens with considerable side effects $(4,5)$. The HIV pandemic and socio-economic factors are the two major drivers of TB disease, with factors such as poor living conditions and sanitation, crowded housing, poor air quality, malnutrition, stress, and co-infections all increasing susceptibility to developing active TB disease (6). Improvement of socio-economic conditions along with development of a more effective vaccine against TB will be critical in controlling this devastating disease.

Almost 100 years ago, in 1921, the first newborn was immunized with a live attenuated strain of the bovine Mycobacterium species, Mycobacterium bovis bacille Calmette-Guérin (BCG), followed by mass vaccination campaigns (7). BCG is partially protective against TB and has immunostimulatory effects that reduce general mortality during the first years of life by enhancing responses to other infectious diseases such as respiratory viruses (8-10). However, the efficacy of BCG against TB varies geographically and BCG does not provide adequate protection against pulmonary disease, the main form of disease manifestation and the cause of transmission (1). The development of a more effective TB vaccine is therefore likely to play a profound role in controlling this disease. As a live vaccine, BCG can also cause local or systemic infection in immunocompromised individuals (11) and is thus contraindicated in individuals who stand to benefit most from vaccination, such as HIV-positive individuals who are at high risk of developing active TB. Hence, the development of a vaccine that is safer for use in immunocompromised individuals is also a high priority.

A number of TB vaccine candidates are under clinical development, and many more have been pre-clinically tested in animal models (12-15). Pre-clinical evaluation of novel vaccine candidates has improved our knowledge of protective responses against $\mathrm{TB}$ and has shown that as a standalone vaccine $\mathrm{BCG}$ is at least as effective as novel subunit vaccines (16). BCG continues to be used in countries where TB is endemic due to its partial efficacy and has an established safety record. Hence, two major strategies in TB vaccine development have been to generate live mycobacterial vaccines with improved efficacy and safety, such as recombinant BCG ( $\mathrm{BBCG}$ ) vaccines, or to boost BCG with subunit vaccines containing $\mathrm{Mtb}$ antigens. This review provides an update on the latest knowledge on BCG and summarizes the rBCG candidates that have been tested against $\mathrm{TB}$ in animal models or clinical trials.

\section{BCG AS A VACCINE AGAINST TB}

Meta-analyses have found that BCG provides on average $50 \%$ protection against TB and is effective for 10-20 years, but efficacy varies between countries and is much lower in adults than in children (17-21). Absence of sensitization to environmental mycobacteria or prior Mtb infection is associated with higher efficacy of BCG against TB (18). BCG is particularly effective against TB meningitis and disseminated TB in infants, with protection against pulmonary TB being much lower (22). The original BCG developed at the Pasteur Institute in Lille, France, was distributed around the world, and continuing passaging led to accumulating genetic mutations and the divergence of numerous substrains (23). These substrains appear to vary in efficacy in animal models, which has been reviewed previously (23). It has been suggested that this could contributes to the variable efficacy seen in different studies; however, a meta-analysis suggests that the type of BCG substrain does not significantly affect efficacy (18). More strikingly, analyses found higher efficacy in colder countries such as UK and Norway and lower efficacy in warmer countries such as India and Indonesia $(18,19,22$, $24,25)$. This variation in efficacy seems to be due to increased exposure to environmental mycobacteria, which appears to reduce reactivity to $\mathrm{BCG}(18,26,27)$. Prior infection with $\mathrm{Mtb}$ also reduces the efficacy of the BCG vaccine (18). People living in $\mathrm{TB}$ endemic countries are more frequently exposed to $\mathrm{Mtb}$, which raises the risk of individuals being infected (28). The HIV pandemic has contributed to increasing the burden of TB (3). Other risk factors for TB disease include diabetes, smoking, alcoholism, indoor air pollution, chronic corticosteroid treatment, malignancy, and malnourishment $(29,30)$. Therefore, these factors probably also contribute to the failure of BCG to protect against disease in some individuals.

Humans are not the only species at risk of TB, as wildlife and farmed animals are also susceptible to infection with various mycobacterial strains. Two species of agricultural importance include M. bovis and Mycobacterium caprae, closely related species of the same clade that cause TB in cattle and goats, and can also be transmitted to humans (31). BCG was first tested and proven effective against virulent $M$. bovis infection in cattle by Calmette and Guerin in 1911 (32), 10 years before its delivery to a human newborn; however, it is not routinely given to cattle to avoid interference with diagnostic tests for M. bovis (32). Recently, it has been shown feasible to distinguish vaccinated from infected animals $(33,34)$. Trials vaccinating large animals with BCG and subunit vaccine boosters have demonstrated that BCG is more protective when administered to neonates and that subunit vaccines can boost protection after BCG prime [reviewed in Ref (32)]. Cows and goats vaccinated with BCG and exposed to natural infection were protected compared to those without vaccination (32). Efficacy was approximately 55-70\%, similar to the estimated efficacy of BCG in humans in Norway and the UK $(19,35,36)$.

Vaccines rely on the generation of memory responses, which result from the clonal expansion and differentiation of antigen-specific lymphocytes (37). T cells can differentiate into effector memory $\mathrm{T}\left(\mathrm{T}_{\mathrm{EM}}\right)$ cells that have effector functions such as cytokine production and migrate to affected tissues, and central memory $\mathrm{T}\left(\mathrm{T}_{\mathrm{CM}}\right)$ cells that home to secondary lymphoid organs, where they can proliferate and differentiate into new effector cells upon re-exposure to antigen. Immunity to Mtb requires $\mathrm{CD}^{+}$and $\mathrm{CD}^{+} \mathrm{T}$ cells producing type I effector cytokines such as IFN- $\gamma$ and TNF- $\alpha$ and their recruitment to the lung (38-43). $\mathrm{T}$ cells that home to the lung tissue and accumulate there, known as tissue resident memory $\left(\mathrm{T}_{\mathrm{RM}}\right)$ cells, are particularly important for immunity to $\mathrm{Mtb}(38,43)$. Mucosal immunization with $\mathrm{BCG}$ induces more $\mathrm{T}_{\mathrm{RM}}$ cells than parental immunization 
(43). In addition, it was recently shown that interleukin (IL)21-dependent memory-like natural killer (NK) cells generated after BCG vaccination were protective against $\mathrm{Mtb}$ challenge (44). Furthermore, innate immune responses are undoubtedly important in resistance against Mtb (45) and increasing evidence suggests a role for antibodies in protection (46-48). There is a fine balance between protective immune responses and excess immunopathology, and the type of immune responses induced is critical, particularly as Mtb can infect recruited myeloid cells such as neutrophils and myeloid-derived suppressor cells (49, 50). The immunology of Mtb infection is illustrated in simplified form in Figure 1. The strengths of BCG as a vaccine are that it induces immune responses against a broad range of mycobacterial antigens, boosts innate immunity by stimulating monocytes, persists for a relatively long time compared to non-live vaccines, and requires no adjuvants $(51,52)$. Its failure to provide sufficient protection against TB may be related to insufficient generation of
$\mathrm{CD}^{+} \mathrm{T}$-cell responses and $\mathrm{CD} 4^{+} \mathrm{T}_{\mathrm{CM}}$ cell responses, which are required for long-term protection against $\mathrm{Mtb}(41,53-57)$. It has been proposed that BCG fails to provide long-term protection, as the rate of TB increases in early adulthood and some studies have shown waning of protection after $10-15$ years $(25,58)$. However, recent meta-analyses suggest that BCG can be effective for 20 years or longer in some populations (19). This is similar to, or even better than, the duration of protection of other commonly used vaccines, which often require boosters every 10 years. However, boosting BCG with repeat doses does not seem to be effective (59). In individuals infected with Mtb or constantly exposed to environmental mycobacteria, vaccine-induced $\mathrm{T}_{\mathrm{CM}}$ cells are under increased pressure and constant exposure to antigens may deplete pools of $\mathrm{T}_{\mathrm{CM}}$ cells by stimulating them to differentiate into effector cells $(56,58)$.

In both mice and humans, the T-cell responses to BCG vaccination are dominated by effector or $\mathrm{T}_{\mathrm{EM}}$ cells rather than $\mathrm{T}_{\mathrm{CM}}$

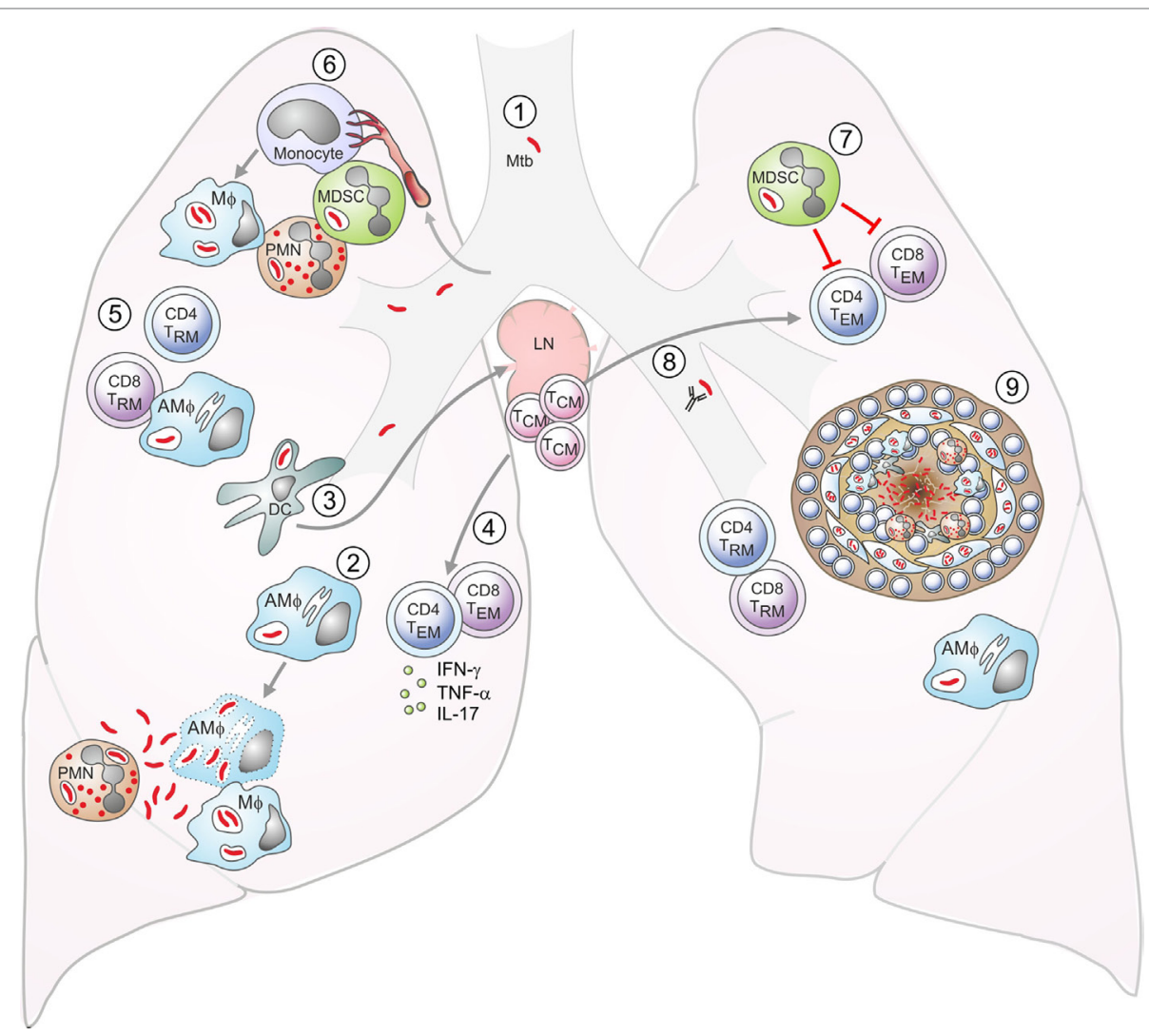

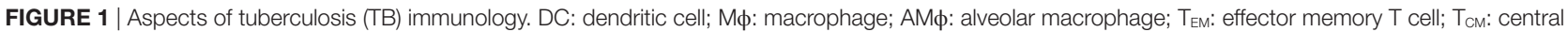
memory T cell; $T_{\mathrm{RM}}$ : resident memory T cell; MDSC: myeloid-derived suppressor cell; PMN: neutrophil. (1) Exposure to Mycobacterium tuberculosis (Mtb) is by the inhalation of infected aerosol droplets generated by coughing. (2) Mtb bacilli primarily live in host macrophages. Alveolar macrophages and other myeloid cells such as DCs can take up bacteria from the airways. If macrophages do not control infection, the bacteria can replicate and kill the cell. Bacteria can also infect neutrophils, which die and can be taken up by macrophages, which subsequently become infected themselves. (3) Infected DCs have delayed migration to the lymph nodes and impaired antigen presentation. In the lymph nodes, they transfer antigens to uninfected bystander DCs, which present the antigens to T cells. (4) Effector $\mathrm{CD}^{+}$and $\mathrm{CD} 8^{+} \mathrm{T}$ cells generated from naive $\mathrm{T}$ cells or from memory $\mathrm{T}$ cells are recruited to the lungs. (5) Effector CD4+ $\mathrm{T}$ cells produce cytokines such as IFN- $\gamma$, interleukin (IL)-17, and TNF- $\alpha$, while CD8 ${ }^{+}$T cells can lyse infected macrophages. IFN- $\gamma$ can activate bacterial killing. (6) Neutrophils, monocytes, or immature myeloid cells with suppressive functions, known as MDSCs are recruited to the lungs. Monocytes can differentiate into inflammatory macrophages or inflammatory DCs. (7) MDSCs aim to limit excessive inflammation by inhibiting T-cell proliferation and function, but they can act as a reservoir for Mtb. (8) Antibodies may also play a role in controlling infection. (9) Eventually, the immune cells form a granuloma around Mtb in an attempt to contain the bacteria. These are the typical lesions observed in the Mtb-infected lung, most commonly in the upper lobes. 
cells $(57,58)$. BCG resides in the phagosome of host cells, and its antigens are therefore primarily processed by major histocompatibility complex (MHC) class II pathways, stimulating $\mathrm{CD}^{+}$ T-cell responses (60). BCG is also a poor inducer of apoptosis, a process of controlled cell death, which promotes the induction of both $\mathrm{CD}^{+}$and $\mathrm{CD}^{+} \mathrm{T}$ cells $(53,55,61)$. In mice, the loss of BCG-mediated protection in the chronic phase coincides with a loss of $\mathrm{CD} 4^{+} \mathrm{T}_{\mathrm{CM}}$ cells and an increase in terminally differentiated, dysfunctional T cells $(41,54)$. Mtb is a slow growing bacterium, and the chronic nature of the disease may lead to T-cell exhaustion-a progressive loss of T-cell function. Thus, an effective vaccine should induce large pools of memory cells that can replenish $\mathrm{T}_{\mathrm{EM}}$ cells. In humans, increasing mycobacterial load coincides with progressive impairment of Mtb-specific CD4 ${ }^{+} \mathrm{T}$-cell responses $(62)(41,54,63,64)$. As exhausted T cells can be restored by inhibiting programmed cell death protein (PD)-1 or stimulating toll-like receptor 2 , it is possible that host-directed therapy to improve T-cell function could be used therapeutically in TB patients, but studies are still ongoing (65). Recently, it was shown that memory $\mathrm{CD} 4^{+} \mathrm{T}$ cells recruited to the lung attenuated Mtb growth in the early stages of disease, but their interaction with Mtb-infected macrophages did not promote their continued proliferation, resulting in only transient protection followed by waning immunity (66). Furthermore, Mtb-infected dendritic cells (DCs) cannot efficiently present antigens and instead transfer antigens to bystander DCs in the lymph nodes, which present the antigens to $\mathrm{T}$ cells (67-69). This causes a delay in activation of memory $\mathrm{T}$ cells and their recruitment to the lung. Overcoming such obstacles to sterilizing immunity against Mtb would improve the efficacy of TB vaccines markedly (68).

Novel vaccines aim to increase the number and quality of $\mathrm{T}_{\mathrm{RM}}$ and $\mathrm{T}_{\mathrm{CM}}$ cells generated $(13,70-72)$. While it was first thought that only live vaccines could generate good $\mathrm{T}_{\mathrm{CM}}$ responses, novel adjuvants administered with $\mathrm{Mtb}$ antigens have also shown success in this regard $(41,70)$. In clinical trials of novel vaccine candidates, it will be important to monitor long-term protective efficacy in populations with different levels of exposure to Mtb (58).

\section{rBCGs AGAINST TB}

A number of rBCGs have been generated and tested for immunogenicity and/or efficacy in animal models. To narrow it down, we will discuss primarily those that have been tested for protective efficacy against Mtb (see Table 1). This includes BCG strains that have been engineered to induce increased immune responses by insertion of genes for Mtb antigens, mammalian cytokines or host resistance factors, insertion of bacterial toxin derived adjuvants, and manipulation of bacterial genes in order to increase antigen presentation and immune activation.

\section{rBCGs Expressing Mtb Antigens}

Analysis of the genetic differences between BCG and Mtb has determined that 16 genomic regions of difference (designated RD1-RD16) have been deleted from BCG substrains, although some substrains do contain $\mathrm{RD} 2, \mathrm{RD} 8, \mathrm{RD} 14$, and $\mathrm{RD} 16$
(104-106). RD1 to RD3 were the first to be identified and are present in virulent $M$. bovis as well as Mtb (104). RD1 is a 9.5-kb segment deleted from all BCG substrains but conserved in all virulent isolates of M. bovis and Mtb, and it regulates multiple genetic loci. The RD1 segment contains the genes for the immunodominant antigens early secretory antigenic target (ESAT)-6 and culture filtrate protein-10 (CFP-10), as well as components of the type VII ESAT-6 secretion system (ESX)-1 required to secrete them $(73,104,107,108)$. RD1 deletion and the loss of the ESX-1 secretion system was a major factor in the original attenuation of BCG $(73,104,107)$. At least five additional T-cell antigens are encoded by RD1 (PE35, PPE68, Rv3871, Rv3878, and Rv3879c), suggesting that RD1 constitutes an immunogenicity island (108). RD2 is a 10.7-kb segment deleted only from substrains derived from the original BCG Pasteur strain after 1925, and it is conserved in $M$. bovis and Mtb. RD2 contains novel repetitive elements and the mpt64 gene, encoding the protein MPT64 which elicits T-cell responses and delayed hypersensitivity reactions in Mtb-infected patients (109). Finally, RD3 is a 9.3-kb segment absent from BCG, present in virulent laboratory strains of $M$. bovis and $\mathrm{Mtb}$, but absent from $84 \%$ of virulent clinical isolates. The loss of RD1 to RD16 means that BCG lacks a number of the antigens of Mtb, and attempts have been made to improve the efficacy of BCG against TB by generating rBCGs expressing antigens particular to Mtb, such as ESAT-6 $(74,75,80,81,110)$. ESAT- 6 not only acts as an antigen but also can induce IL-18-dependent IFN-gamma secretion by Mtb antigen-independent memory $\mathrm{CD} 8^{+} \mathrm{T}$ cells and NK cells (111). Furthermore, rBCGs over-expressing antigens that are found in both BCG and Mtb, such as antigen 85B (Ag85B), have been generated in an attempt to boost immune responses against shared mycobacterial antigens. In support of the fact that including Mtb antigens improves the protective efficacy of mycobacterial strains, removing CFP-10 and ESAT-6 from the attenuated Mtb-derived MTBVAC strain reduced its protection against Mtb in mice to that of BCG levels (112). MTBVAC is an Mtb strain attenuated by independent deletions of the phoP and fadD26 virulence genes.

An rBCG over-expressing ESAT-6 induced stronger IFN- $\gamma$ responses than parental BCG but did not improve protection against aerosol Mtb challenge in guinea pigs (75). In contrast, rBCG30, over-expressing the shared immunodominant Ag85B, improved protection against $\mathrm{Mtb}$ in a guinea pig model relative to BCG (76). Ag85B is one of the three similar secreted mycolyltransferases that are important for bacterial wall synthesis (113). A Phase I clinical trial was completed where 35 adults were randomized to receive rBCG30 or parental BCG in a doubleblind fashion (77). The vaccine was well tolerated, and expansion and IFN-gamma production of Ag85B-specific CD4 ${ }^{+}$and $\mathrm{CD}^{+}$ $\mathrm{T}$ cells were increased in the rBCG30 immunized individuals compared to those immunized with parental BCG (77). To improve the safety of rBCG30 for use in immunocompromised individuals, a new construct, rBCG(mbtB30) was developed, which has disrupted synthesis of the siderophore mycobactin, preventing normal iron acquisition (78). This strain is mycobactin-dependent but can undergo limited replication if sufficient ferric mycobactin is provided. It was shown to be safer than BCG in immunocompromised severe combined immunodeficiency 
BCG:RD1-2F9/BCG:RD1/

BCG:ESX-1

\begin{tabular}{|c|}
\hline rBCG E6 \\
\hline rBCG30 \\
\hline rBCG(mbtB30) \\
\hline rBCG-1173:A \\
\hline rBCG:XB \\
\hline (H)PE- $\triangle M P T 64-B C G$ \\
\hline
\end{tabular}

Bacille Calmette-Guérin (BCG) with the RD1 gene cluster inserted (Rv3861-Rv3885). Expresses early secretory antige ic target-6 (ESAT-6) and culture filtrate protein-10 (CFP10)

Mice: comparable efficacy in the lungs, moderate decrease in spleen bacterial burdens. Increased virulence rBCG over-expressing antigen ESAT-6 rBCG over-expressing antigen 85B (Ag85B)

Guinea pigs: strong decrease in spleen bacterial loads, reduced pathology Guinea pigs: comparable protection to BCG

Guinea pigs: increased survival

Safe and immunogenic in Phase I clinical trials

Guinea pigs: slight decrease in bacteriat burdens

$(78)$

rBCG over-expressing Ag85B, with disrupted synthesis of the siderophore mycobactin, preventing normal iron acquisition rBCG expressing Ag85A

rBCG expressing Ag85B and latency antigen $\mathrm{HspX}$

Mice: safer in severe combined immunodeficiency (SCID) mice

Mice: slight decrease in bacterial burdens

Mice: strong decrease in bacterial burdens

列 PGRS33 protein of Mtb that localizes to the cell wall rBCG:ESX-1 variant with mutations in the ESAT-6 gene

Mice: moderate decrease in spleen bacterial burdens, no difference in lung bacterial burdens.

Attenuated

Guinea pigs: strong decrease in spleen bacterial burdens

BCG:ESX-1 Mmar $^{\text {M }}$

rBCG with the insertion of the esx1 locus of Mycobacterium marinum

(80)

(80)

BCG-IL-4, BCG-IL-6, BCG-GM- rBCG expressing murine interleukin (IL)-4, IL-6, GM-CSF, IFN- $\gamma$, No efficacy data

BCG secreting IL-2

BCG secreting IL-2

rBCG-mlL-18

BCG secreting mouse IL-18

BCG-IL-18 BCG secreting mouse IL-18

rBCG/L-18

rBCG expressing IL-18

rBCG/L-2

rBCG expressing IL-2

BCG-IFN-gamma

rBCG secreting murine IFN- $\gamma$

rBCG-Ag85B-IL-15

rBCG expressing a fusion protein of Ag85B and IL-15

No efficacy data

Mice: attenuated. Efficacy against Mtb not tested

Mice: no difference in virulence compared to BCG. Efficacy against Mtb not tested

Mice: decreased protective efficacy against virulent Mycobacterium bovis challenge compared to BCG

Mice: did not increase protective efficacy against the virulent $M$. bovis challenge compared to BCG

Mice: did not increase protective efficacy against Mtb compared to BCG

Mice: decreased bacterial burdens after intratracheal Mtb challenge, compared to BCG-Ag85B. No comparison performed with BCG

rBCG-Ag85B-ESAT-6-TNF- $\alpha$ rBCG expressing the fusion protein Ag85B-ESAT-6-TNF- $\alpha$ Efficacy against Mtb not tested

rBCG Ag85B-ESAT-6-IFN- $\gamma$ rBCG strain expressing the fusion protein Ag85B-ESAT-6-IFN- $\gamma$

BCGi

The Ipr1 (intracellular pathogen resistance 1) gene was inserted Mice: decreased bacterial loads in the lungs and spleens after Mtb challenge into BCG

rBCG(MCP-3) Insertion of the gene for the chemokine monocyte chemotactic

Mice: increased safety in immunodeficient mice. Efficacy comparable to BCG protein $3(\mathrm{MCP}-3)$ into BCG

VPM1002 (BCG $\triangle$ ureC:hly) BCG expressing the Listeria monocytogenes protein listeriolysin $\mathrm{O}(\mathrm{LLO})$ instead of urease $\mathrm{C}$

Mice: increased safety in both immunocompetent and immunodeficient mice. Moderate to strong decreased bacterial loads and pathology compared to BCG

Safe in guinea pigs, rabbits, and non-human primates

Successfully passed Phase II clinical trials

BCG $\Delta$ ureC:hly $\Delta$ nuoG/ BCG $\Delta$ ureC:hly with deletion of nuoG, an anti-apoptotic gene

VPM1002 $\triangle$ NUOG 
(SCID) mice and was slightly more protective against Mtb than parental BCG in guinea pigs (78).

Other rBCGs expressing Mtb antigens that provided increased protection against Mtb in mice include rBCG expressing Ag85A (79), rBCG expressing Ag85B and latency antigen HspX (rBCG:XB)(80), and rBCG expressing MPT64 fused to the PE domain of the PE_PGRS33 protein of Mtb that localizes to the cell wall ((H)PE- $\triangle$ MPT64-BCG) (81). In another approach, co-administration of an $\mathrm{rMTb} 72 \mathrm{~F}$ fusion protein (composed of Mtb32 and Mtb39 antigens) in an AS02A adjuvant together with BCG increased survival and decreased lung pathology in guinea pigs (110). A small number of antigens feature frequently in the makeup of vaccine candidates generated for pre-clinical and clinical evaluation, with six of the eight subunit vaccines in clinical trials containing an Ag85 protein (14). Current research therefore aims to identify novel antigens and broaden antigen selection for vaccine design.

\section{rBCGs Complemented with ESX-1 Variants}

As mentioned in the previous section, BCG lacks the RD1 and thus a functional ESX-1 secretion system and the antigens ESAT-6 and CFP-10, which form a heterodimeric complex and act as virulence factors $(73,104,107,108)$. ESX-1 is involved in host-pathogen interactions, as access of bacterial antigens to the cytosol influences both bacterial virulence and host immune recognition $(73,83,114)$. An rBCG complemented with the complete RD1 locus (BCG:RD1, also known as BCG:ESX-1) provided better protection against Mtb challenge in both mice and guinea pigs than parental BCG, with reduced lung pathology and dissemination of bacteria (74). However, insertion of the Mtb es $x-1$ locus into BCG leads to increased virulence in immunodeficient mice and prolonged persistence in immunocompetent mice (74). This issue was approached by introducing mutations into the esxA gene (encoding ESAT-6) of BCG:ESX-1 (82) or by inserting the esx-1 locus of Mycobacterium marinum, which has reduced virulence, into BCG (83). A BCG:ESAT-L28A/L29S strain carrying modifications at residues Leu(28)-Leu(29) of the ESAT protein was strongly attenuated in mice and demonstrated protective efficacy against Mtb challenge in mice and guinea pigs, with similar lung bacterial burdens but a strong reduction in spleen bacterial burdens (82). BCG:ESX-1 $1^{\mathrm{Mmar}}$ increased protective efficacy compared to BCG in mice, demonstrating similar immunogenicity and efficacy to BCG:ESX ${ }^{\mathrm{Mtb}}$ but was as safe as parental BCG (83). Compared to BCG Danish, BCG:ESX-1 ${ }^{\text {Mmar }}$ reduced bacterial loads in lungs and spleens by an additional log after a challenge with Mtb HN878 (Beijing family) and Mtb strain M2 (Harlem family). Expression of ESX-1 ${ }^{\text {Mmar }}$ induced the cGas/STING/TBK1/IRF-3/type I interferon axis and enhanced AIM2 and NLRP3 inflammasome activity, leading to increased proportions of mycobacteria-specific cytokine-producing $\mathrm{CD}^{+}$ Th1 cells and $\mathrm{CD}^{+} \mathrm{T}$ cells.

\section{rBCGs Expressing Host Immunomodulatory Molecules}

In an effort to increase host responses to mycobacterial antigens following BCG vaccination, a number of rBCGs have been generated expressing functional mammalian cytokines or other host 
molecules $(84,85,87,93)$. Cytokine-producing rBCG strains have also been generated with the aim of testing them in intravesical BCG immunotherapy for bladder cancer, which seems to require the activation of Th1 responses for efficacy $(86,115,116)$. Most murine cytokines tested could be produced and secreted by BCG and were functional (84). Splenocytes stimulated with IL-2 secreting BCG produced increased IFN- $\gamma$ compared to those stimulated with BCG (85). A study tested rBCGs expressing murine IL-4, IL-6, GM-CSF, IFN- $\gamma$, and IL-2 and found that BCGs secreting IL-2, IFN- $\gamma$, or GM-CSF were more potent stimulators of responses to $\mathrm{PPD}$ than $\mathrm{BCG}$, with splenocytes from mice immunized with these strains producing large amounts of IFN- $\gamma(84)$. In addition, two independent studies demonstrated that $\mathrm{rBCG}$ strains expressing IL-18, a cytokine that acts in synergy with IL-12 to induce IFN- $\gamma$ (88), promoted IFN- $\gamma$ production by splenocytes in response to $\operatorname{PPD}(86,87)$. In one of these studies, mice infected with rBCG-mIL-18 had decreased bacterial loads compared to mice infected with parental BCG (86), whereas in the other, they did not (87). None of the aforementioned strains were tested for protective efficacy against Mtb challenge; however, rBCGs expressing IL-2 or IL-18 were tested against infection with virulent M. bovis (88). In this study, rBCG/IL-18 induced less IFN- $\gamma$ than BCG and had lower protective efficacy against $M$. bovis challenge compared to BCG. Despite inducing increased Th1 responses and protecting against intranasal challenge with BCG, immunization with $\mathrm{rBCG} / \mathrm{IL}-2$ did not increase protective efficacy against the virulent $M$. bovis challenge. Similarly, when IFN- $\gamma$-deficient mice were infected via aerosol with $\mathrm{rBCG}$ secreting murine IFN- $\gamma$, they had reduced bacterial loads and more differentiated granulomas compared to mice infected with the control rBCG containing vector only, demonstrating the potential to influence disease outcomes (89). However, subsequent challenge of IFN- $\gamma^{-/-}$mice with Mtb demonstrated that $\mathrm{rBCG}$ secreting IFN $-\gamma$ did not provide additional protection against Mtb compared to BCG-vector. In this study, IFN- $\gamma$ was only produced locally and local production was insufficient for improving systemic immune responses. Overall, conferring upon BCG, the ability to secrete cytokines does not seem to enhance its protective efficacy, probably because of the amount of cytokine secreted and its locality.

In another strategy, rBCGs expressing combinations of cytokines and antigens, sometimes in the form of fusion proteins (90-92), have also been generated. The rBCG strain expressing the fusion protein Ag85B-ESAT-6-IFN- $\gamma$ only slightly reduced bacterial burdens after Mtb challenge compared to BCG (92). rBCG-Ag85B-ESAT-6-TNF- $\alpha$ increased IFN- $\gamma$ secreting cells, but protection was not measured (91). More promising was an rBCG expressing a fusion protein of Ag85B and IL-15, a cytokine important for the proliferation and survival of memory $\mathrm{CD}^{+}$ T cells (rBCG-Ag85B-IL-15), which was found to increase numbers of IFN- $\gamma$-producing $\mathrm{CD} 44^{+} \mathrm{CD} 4^{+}$and $\mathrm{CD} 44^{+} \mathrm{CD} 8^{+} \mathrm{T}$ cells and decrease bacterial burdens after intratracheal $\mathrm{Mtb}$ challenge, compared to BCG-Ag85B, although comparison to BCG was not performed (90).

Genes for other host-derived immunoregulatory molecules have also been inserted into BCG. In one study, the Ipr1 (intracellular pathogen resistance 1) gene was inserted into BCG to produce $\mathrm{rBCGi}$ (93). Irp1 is an IFN-regulated gene that enhances macrophage resistance to intracellular pathogens such as Mtb and Listeria monocytogenes and is not expressed in susceptible $\mathrm{C} 3 \mathrm{HeB} /$ FeJ mice (117). Vaccination of $\mathrm{C} 3 \mathrm{HeB} / \mathrm{FeJ}$ mice with $\mathrm{rBCGi}$ was more protective against Mtb infection than BCG, with decreased bacterial loads in the lungs and spleens of BCGi-vaccinated mice. Gene expression analysis of 113 immune-related genes demonstrated 20 differentially expressed genes with greater than twofold change between rBCGi and BCG-vaccinated groups. In another study, insertion of the gene for the chemokine monocyte chemotactic protein 3 (MCP-3) into BCG did not improve its efficacy, but increased its safety, since immunodeficient mice infected with $\mathrm{rBCG}(\mathrm{MCP}-3)$ survived longer than mice infected with the parental BCG (94).

\section{VPM1002 and Second-Generation Derivatives}

In previous reviews, we have discussed the development of VPM1002 (BCG $\Delta$ ureC:hly) from the laboratory through to clinical trials in detail $(118,119)$. Essentially, VPM1002 is an rBCG that has been engineered to express the L. monocytogenes protein listeriolysin $\mathrm{O}$ (LLO) instead of urease C. Urease C inhibits acidification of the phagosome by converting urea to ammonia, preventing phagosome maturation (120-122). This activity inhibits trafficking of MHCII to the cell surface resulting in a reduced MHCII expression and antigen presentation (120). LLO is a cholesterol-binding, pore-forming protein that allows escape of L. monocytogenes from the phagosome (123). It requires acidic $\mathrm{pH}$ for optimal activity, which can be achieved by deletion of urease C (95). Expression of LLO in the rBCG causes perturbation to the phagosome (Figure 2) and leakage of bacterial DNA into the cytosol, triggering activation of the AIM2 inflammasome, and increased autophagy and apoptosis (124). Access of bacterial antigens to the cytosol increases its availability to the MHC class I antigen presentation pathway and promotes cross-presentation $(69,125)$. In mice, VPM1002 induces better protection, providing a strong increase in efficacy compared to BCG $(42,96)$. It also provides protection as a post-exposure vaccine (97). Furthermore, it is attenuated, with increased safety in both immunocompetent and immunodeficient mice $(95,96)$. Phase I and Phase II clinical trials have demonstrated its safety and immunogenicity in humans, including neonates, and a Phase II/III efficacy trial as a vaccine against recurrent TB has commenced (119).

While VPM1002 has progressed through the development pipeline, next-generation derivatives of this promising candidate have been developed and tested in pre-clinical studies, with the aim of further enhancing immunogenicity and/or safety (126). The most successful of these so far is VPM1002 $\Delta$ nuoG, which increased protection compared to its parental strain $\mathrm{rBCG}$ $\Delta$ ureC:hly in mice while maintaining safety (96). The nuoG gene codes for a subunit of the non-essential respiratory enzyme complex NADH dehydrogenase type I and was identified as an anti-apoptotic virulence gene after gain-of-function screening using an $M$. smegmatis mutant library following by generation of Mtb H37Rv mutants (61). Deletion of nuoG from Mtb decreased its virulence and lead to increased apoptosis at day 14 post-infection. The mechanism was TNF- $\alpha$ dependent and 


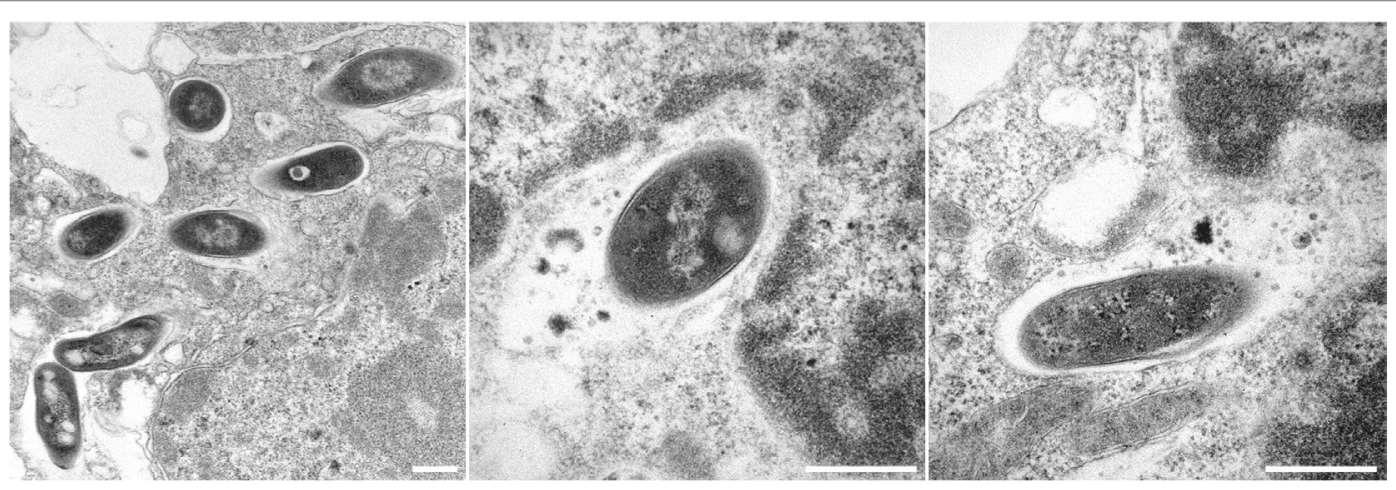

FIGURE 2 | Electron micrographs showing Bacille Calmette-Guérin (BCG) $\Delta$ ureC:hly inside host macrophages. All scale bars represent 0.5 $\mu$ m. Left panel: BCG $\Delta u r e C: h l y$ within phagosomes after uptake by host cells. Middle and right panels: Phagolysosomal fusion after the infection of host cells with recombinant BCG $\Delta$ ureC:hly.

relied on NADPH oxidase (NOX2)-dependent reactive oxygen species (ROS) (127). Subsequently, it was found that deletion of the $n u o G$ gene from both BCG and VPM1002 enhanced protective efficacy against Mtb in mice, with VPM1002 $\Delta$ nuoG having strongly increased efficacy compared to BCG-vaccinated mice (96). Intriguingly, as well as increasing apoptosis, deletion of $n u o G$ also increased the recruitment of the autophagy protein microtubule-associated protein 1A/1B-light chain 3 (LC3) to the live vaccine strains, suggesting that type I NADH dehydrogenase has an additional role in inhibition of autophagic pathways. LC3-associated phagocytosis, which involves conjugation of LC3 to phagosomes and subsequent phagolysosomal fusion, requires NOX2 activity and the production of ROS. Therefore, as type I NADH dehydrogenase inhibits ROS, it is possible that it also inhibits LC3-associated phagocytosis. However, similar persistence of VPM1002 and VPM1002 AnuoG strains in mice suggested that inflammasome or apoptosis-mediated mechanisms induced by both strains were primarily responsible for the strain attenuation. The increased efficacy of VPM1002 $\Delta n u o G$ compared to VPM1002 was associated with increased CD4 ${ }^{+}$ $\mathrm{T}_{\mathrm{EM}}$, follicular $\mathrm{T}$ helper cells and germinal center $\mathrm{B}$ cells (96).

Another approach to improve the efficacy of VPM1002 was to express the latency antigens Rv2659c, Rv3407, and Rv1733c in this strain (98). Rv2659c, encoded by Mtb and not BCG, is expressed during nutrient deprivation, while Rv1733 and Rv3407, present in both BCG and Mtb, are expressed during hypoxia and reactivating disease in a mouse model of $\mathrm{TB}$, respectively. Expression of the three latency antigens in the rBCG $\Delta$ ureC: :hly (pMPIIB01) strain improved long-term efficacy against challenge with a clinical Mtb strain, with reduced bacterial burdens compared to the parental strain in both lung and spleen at day 200 post-infection after intra-dermal vaccination of mice, as well as decreased lung pathology. The strain was not compared to BCG but showed a strong reduction in bacterial loads compared to unvaccinated mice.

Another second-generation construct, BCG $\Delta u r e C: h l y \Delta p d x 1$, or VPM1002 $\Delta p d x 1$, was generated in an attempt to further improve the safety of the vaccine so that it might be suitable for immunization of immunocompromised individuals such as
$\mathrm{HIV}^{+}$infants and adults and HIV-exposed neonates, who are at higher risk of developing TB (99). VPM1002 $\Delta p d x 1$ is deficient in pyridoxine synthase, an enzyme required for synthesis of the essential vitamin B6, and therefore is auxotrophic for vitamin B6 in a concentration dependent manner. VPM1002 $\Delta p d x 1$ was profoundly attenuated, being safer in immunocompromised SCID mice compared to its parental strain. In addition, it demonstrated reduced dissemination in wild-type mice, which was partially reversed by dietary supplementation with vitamin B6. Immune responses to the strain were also dependent on vitamin B6 supplementation. Protective efficacy against Mtb was similar to BCG at day 30 but was lost by day 180 ; however, a homologous prime-boost regimen afforded similar protection to BCG. Protection depended on a dietary source of vitamin B6 at early time points following Mtb challenge, but protection at 180 days post-challenge with Mtb $\mathrm{H} 37 \mathrm{Rv}$ and 160 days post challenge with Mtb Beijing/W remained independent from vitamin B6 supplementation, suggesting that it relied on immune responses generated at early time points.

As discussed earlier, there are several examples of rBCGs expressing mammalian cytokines, which promote increased immune responses (116). Therefore, Rao et al. attempted to further increase the immunogenicity of BCG $\Delta u r e C$ :hly by generating BCG $\Delta$ ureC:hly derivatives expressing the cytokines IL-7 and IL-18 (100). IL-7 and IL-18 play a role in immunity to Mtb infection (128-130). IL-7 is required for T-cell development (131), and rIL-7 influences recall T-cell responses to Mtb infection (132). IL-18 induces Th1 responses (including IFN-gamma and TNF- $\alpha$ secretion), together with IL-12 (133). IL-18-deficient mice are susceptible to TB $(128,134)$ and BCG infection $(134)$. Previously, splenocytes of mice vaccinated with $\mathrm{rBCG}$ expressing IL-18 produced higher amounts of Th1 cytokines after stimulation with mycobacterial antigens than splenocytes of mice vaccinated with parental BCG (87). Furthermore, increased IL-18 mRNA was detected after vaccination with BCG $\Delta$ ureC:hly and BCG $\Delta$ ureC:hly $\Delta n u o G$, which have increased efficacy compared to $\operatorname{BCG}(96,124)$.

Growth assays demonstrated that expression of IL-7 or IL-18 did not compromise intracellular fitness of BCG $\Delta$ ureC:hly_hIL7 
and BCG $\Delta$ ureC:hly_hIL18 (100). Secretion of pro-inflammatory cytokines including IL-6, TNF- $\alpha$, and G-CSF was increased in DCs infected with BCG $\Delta$ ureC:hly_hIL18 compared to BCG, although in co-cultures T-cell activation was not influenced. Similarly, BCG $\Delta$ ureC:hly_hIL18 immunized mice showed up-regulation of proinflammatory cytokines IL-6, KC, CCL5, IL-2, and G-CSF compared to those vaccinated with BCG. At day 60 , all strains on the BCG $\Delta$ ureC:hly background induced similar numbers of CD40Lexpressing $\mathrm{CD}^{+} \mathrm{T}$ cells in the lungs, but BCG $\Delta$ ureC:hly_hIL18 and BCG $\Delta$ ureC:hly_hIL7 induced increased CD40L ${ }^{+}$TNF- $\alpha^{+}$and CD $40 \mathrm{~L}^{+} \mathrm{TNF}-\alpha^{+} \mathrm{IFN}-\gamma^{+} \mathrm{CD} 4^{+}$T cells compared to BCG $\Delta$ ureC:hly between 30 and 60 days post-vaccination. Efficacy, measured by bacterial loads, was comparable to the parental strain. Therefore, expression of hIL-7 or hIL-18 by VPM1002 did not further improve protection. Suggested reasons were poor secretion of hIL-7 and hIL-18 and overload of the mycobacterial export machinery due to the use of the same export system (PgroEL2-Ag85BSS) for both LLO and the cytokines.

VMP1002, VPM1002 $\Delta n u o G$, and VPM1002 $\Delta p d x 1$ are currently being tested for safety and protective efficacy against $M$. caprae infection in goats by the Friedrich Loeffler Institute in Germany (Menge et al., unpublished data). Results should be available in 2018 .

\section{AEREAS-401 AND AERAS-422}

AERAS-401 is an rBCG expressing the cholesterol-binding cytoslysin perfringolysin $\mathrm{O}$ (Pfo), a pore-forming protein normally secreted by Clostrididium perfringens (101, 135). Pfo interacts with membranes at both low and neutral $\mathrm{pH}$, although low $\mathrm{pH}$ enhances Pfo membrane binding, oligomerization, and pore formation (136). Generation of this BCG strain (BCG1331

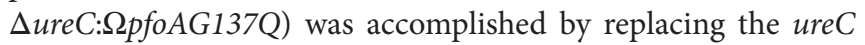
gene with the PfoAG137Q gene under the control of the Ag85B promoter (101). AERAS-401 secreted biologically active Pfo, associated with lysis of the endosome compartment, and had a good safety profile in immunocompromised SCID mice. A second-generation derivative of AEREAS-401, AREAS-422 (research strain AFRO-1), was then generated by incorporating genes coding for Ag85A, Ag85B, and TB10.4, into AERAS-401 in order to combine increased access of antigens to the cytosol with over-expression of Mtb antigens (101). AERAS-422 enhanced immune responses in both mice and guinea pigs compared to BCG. A short-term challenge experiment with a laboratory strain of Mtb in mice revealed no differences in bacterial loads in lungs and spleen after immunization with AERAS-422 compared with BCG, but challenge of vaccinated mice with the hypovirulent Mtb strain HN878 demonstrated increased survival after immunization with AERAS-442 compared to BCG (101). AERAS-422 was subsequently tested in Phase I clinical trials (137). It induced more potent immune responses than BCG, but immunization with AERAS-422 at the highest inoculum was associated with the development of shingles (varicella-zoster virus reactivation) in two of the eight healthy volunteers, and the study was discontinued. Whole blood stimulation with BCG demonstrated that both of the volunteers who developed shingles displayed five- to tenfold higher IFN- $\gamma$ responses compared to the other recipients, and it was suggested that the effects of IFN- $\gamma$ on type I IFN responses (required for antiviral immunity) should be investigated. In the trial, earlier and more robust NK and cytotoxic T-cell responses correlated with increased mycobacterial growth inhibition, suggesting that NK cells and cytotoxic T cells may serve as a target for improved vaccines against TB. In contrast, increased expression of myeloid and pro-inflammatory genes was negatively associated with mycobacterial growth inhibition.

\section{rBCGs Expressing Bacterial Toxins}

Bacterial toxins and toxin derivatives possess immunostimulatory properties and activate immune responses to bystander antigens when present simultaneously, but their toxicity renders them unsuitable for use as adjuvants in humans (138). An example is cholera toxin (CT), which is a potent mucosal adjuvant but is not suitable for use in humans as its inflammatory nature induces adverse events (68). Mice immunized with rBCG expressing CT $\mathrm{B}$ developed increased levels of anti-BCG IgA and IgG responses compared to those immunized with parental BCG, associated with increased TGF- $\beta$ production (139). In another study, CT enhanced IL-17 when administered together with BCG, and this was associated with increased protection against Mtb challenge (68). While CT cannot be used in humans, the study highlighted the potential role of mucosal adjuvants in protection against TB.

Escherichia coli heat labile toxin (LT) is another mucosal adjuvant, shown to promote antigen presentation, T-cell proliferation, cytokine production, and mucosal IgA and IgG responses (140). Detoxification of the A subunit by genetic modification results in a potent, non-toxic mucosal adjuvant with no toxicity in mice, guinea pigs, and macaques $(138,141-144)$. Detoxified LT has a good clinical safety record after oral and percutaneous administration, but nasal administration is not recommended because it is associated with an increased risk of transient peripheral facial nerve palsy $(145,146)$. Additional safety studies for other routes of administration would be prudent, considering the adverse effects after intranasal immunization were not detected in initial trials (144).

Recently, an rBCG (rBCG-LTAK63lo) was generated to express low levels of a non-toxic derivative of LT (LTAK63) (102). Vaccination with rBCG-LTAK63lo induced increased Th1 cytokines and IL-17 in the lung compared to BCG. After intratracheal challenge with a laboratory strain of $\mathrm{Mtb}$, mice had greatly reduced bacterial burdens compared to BCG at day 30 post-challenge, and at a high challenge dose, mice immunized with rBCG-LTAK63lo had reduced bacterial loads and increased survival. rBCG-LTAK63lo also increased protection against challenge with a virulent Mtb Beijing isolate.

\section{BCG $\Delta z m p 1$}

Interleukin- $1 \beta$ is a major pro-inflammatory cytokine that is activated by cleavage of a pro-IL- $1 \beta$ precursor by caspases activated by assembly of the inflammasome, an inflammatory caspase-activating multi-protein complex (147). Mtb inhibits inflammasome activation and IL-1 $\beta$ processing by a mechanism involving the product of the virulence gene $z m p 1$, a putative $\mathrm{Zn}(2+)$ metalloprotease (147). Accordingly, infection with Mtb deficient in $z m p 1$ triggers activation of the inflammasome, increased IL-1 $\beta$ 
TABLE 2 | Boosters to bacille Calmette-Guérin (BCG).

\begin{tabular}{|c|c|c|c|}
\hline Prime & Boost & Protective efficacy versus BCG alone & Reference \\
\hline BCG & $\begin{array}{l}\text { Nanoemulsion mucosal adjuvant with early secretory antigenic } \\
\text { target-6 (ESAT-6) and antigen 85B (Ag85B) }\end{array}$ & Mice: bacterial loads similar, reduced lung pathology & $(154)$ \\
\hline BCG & H56 fusion protein (Ag85B-ESAT-6-Rv2660c) with CAF01 adjuvant & Mice: moderate decrease in bacterial burdens & $(155)$ \\
\hline BCG & H1 fusion protein (Ag85B-ESAT-6) with CAF01 adjuvant & Mice: moderate to strong decrease in bacterial burdens & $(41,155)$ \\
\hline BCG & H4 fusion protein (Ag85B-TB10.4) with IC31 adjuvant & $\begin{array}{l}\text { Guinea pigs: moderate decrease in bacterial burdens, } \\
\text { increased survival } \\
\text { Mice: decreased bacterial burdens (slight in lungs, } \\
\text { moderate in spleens) }\end{array}$ & $(156,157)$ \\
\hline BCG & H56 fusion protein (Ag85B-ESAT-6-Rv2660c) with IC31 adjuvant & $\begin{array}{l}\text { Macaques: reduced lung pathology, clinical disease } \\
\text { and extrapulmonary dissemination, increased survival, } \\
\text { prevention of reactivation of latent infection }\end{array}$ & $(158)$ \\
\hline BCG & Ag85B-ESAT-6 with LTK63 adjuvant & Mice: slight decrease in bacterial burdens & $(141)$ \\
\hline BCG & Mtb72F fusion protein DNA (Mtb32 and Mtb39 antigens) & Guinea pigs: decreased lung pathology & $(110)$ \\
\hline BCG & $\begin{array}{l}\text { ID93 fusion protein (Rv1813, Rv2608, Rv3619, and Rv3620) with } \\
\text { glucopyranosyl lipid adjuvant (GLA) stable emulsion (SE) }\end{array}$ & Guinea pigs: reduced pathology, increased survival & $(159)$ \\
\hline BCG & $\begin{array}{l}\text { Mycobacterium tuberculosis (Mtb) antigens Rv0447, Rv2957, and } \\
\text { Rv2958 (no adjuvant) }\end{array}$ & Mice: slight decrease in lung bacterial burdens & $(16)$ \\
\hline $\mathrm{BCG}$ & $\begin{array}{l}\text { CMFO fusion protein (Rv2875-Rv3044-Rv2073c-Rv0577) with DMT } \\
\text { adjuvant }\end{array}$ & $\begin{array}{l}\text { Mice: strong decrease in bacterial burdens, protection } \\
\text { after reactivation by glucocorticosteroids }\end{array}$ & $(160)$ \\
\hline BCG & $\begin{array}{l}\text { SRL172/DAR-901 [inactivated whole cell booster from NTM } \\
\text { (Mycobacterium obuense)] }\end{array}$ & Mice: no difference in bacterial loads & $(161)$ \\
\hline BCG & Rv2299c-ESAT-6 fusion protein & $\begin{array}{l}\text { Mice: slight decrease in lung bacterial burdens, reduced } \\
\text { pathology (HN878 challenge) }\end{array}$ & $(151)$ \\
\hline $\mathrm{BCG}$ & Human adenovirus 5 with Ag85A (Ad5Ag85A), i.m and i.n. & $\begin{array}{l}\text { Mice: i.m. boosting did not increase protection, but } \\
\text { intranasal boosting reduced lung and spleen bacterial } \\
\text { burdens moderately and strongly, respectively }\end{array}$ & $(162)$ \\
\hline $\mathrm{BCG}$ & attenuated Listeria monocytogenes vector expressing Ag85B (rLm30) & $\begin{array}{l}\text { Guinea pigs: no difference } \\
\text { Mice: slightly reduced lung bacterial burdens }\end{array}$ & $(163)$ \\
\hline BCG & recombinant adenovirus vaccine expressing Ag85B (rAdv30) & $\begin{array}{l}\text { Guinea pigs: no difference } \\
\text { Mice: slightly reduced lung bacterial loads at early time } \\
\text { point ( } 6 \text { weeks post-challenge) only }\end{array}$ & $(163)$ \\
\hline$B C G$ & $\begin{array}{l}\text { Six fusion proteins [ESAT-6-Ag85B-MPT64190-198-Mtb8.4 (EAMM), } \\
\text { Ag85B-MPT64190-198-Mtb8.4 (AMM), Mtb10.4-HspX (MH), } \\
\text { ESAT-6-Mtb8.4 (EM), Mtb10.4-Ag85B, ESAT-6-Ag85B (MAE), and } \\
\text { ESAT-6-RpfE (ER)] in adjuvant composed of N,N'-dimethyl- } N, N^{\prime}- \\
\text { dioctadecylammonium bromide (DDA), polyribocytidylic acid (poly I:C), } \\
\text { and gelatin }\end{array}$ & $\begin{array}{l}\text { Mice: decreased lung pathology in EAMM boosted mice. } \\
\text { Slightly decreased lung bacterial burdens in EAMM or } \\
\text { AMM boosted mice }\end{array}$ & $(164)$ \\
\hline$B C G$ & $\begin{array}{l}\text { DNA encoding } \beta \text {-defensin } 2 \text { and antigens ESAT- } 6 \text { and Ag8B (pDE and } \\
\text { pDA) }\end{array}$ & Mice: increased survival, decreased lung pathology & $(165)$ \\
\hline BCG & Sendai virus with Ag85A and Ag85B & $\begin{array}{l}\text { Mice: slightly reduced bacterial loads, reduced lung } \\
\text { pathology }\end{array}$ & $(166)$ \\
\hline $\mathrm{BCG}$ & Mycobacterium indicus pranii (MIP), s.c. or aerosol & $\begin{array}{l}\text { Guinea pigs: decreased lung pathology } \\
\text { Mice: MIP boosters moderately reduced lung bacterial } \\
\text { burdens }\end{array}$ & $(167)$ \\
\hline$B C G$ & MVA85A (vaccinia based vector expressing Ag85A) & $\begin{array}{l}\text { Mice: no difference } \\
\text { Guinea pigs: no difference }\end{array}$ & $(152,168)$ \\
\hline BCG i.n. & MVA85A i.n. or BCG i.n. & Mice: strong decrease in bacterial burdens & $(169)$ \\
\hline BCG & $\begin{array}{l}\text { Chimpanzee adenovirus with Ag85A (ChAdOx185A), with and without } \\
\text { MVA85A boost }\end{array}$ & $\begin{array}{l}\text { Mice: lung bacterial burdens were slightly improved after } \\
\text { intranasal boosting with both ChAdOx185A and MVA85A }\end{array}$ & $(153)$ \\
\hline $\begin{array}{l}\text { rBCG expressing } \\
\text { PPE protein Rv3425 }\end{array}$ & Rv3425 & $\begin{array}{l}\text { Mice: slightly reduced lung bacterial burden, decreased } \\
\text { lung pathology }\end{array}$ & $(170)$ \\
\hline
\end{tabular}


TABLE 2 | Continued

\begin{tabular}{|c|c|c|c|}
\hline Prime & Boost & Protective efficacy versus BCG alone & Reference \\
\hline $\begin{array}{l}\text { rBCG secreting } \\
\text { Ag85B-ESAT-6 }\end{array}$ & LTK63-adjuvanted Ag85B-ESAT-6 & Guinea pigs: no increase in protection & $(142)$ \\
\hline VPM1002 & MVA85A & Mice: no difference & (168) \\
\hline $\begin{array}{l}\text { rBCG expressing } \\
\text { ESAT-6 }\end{array}$ & DNAE6 (ESAT-6 DNA) & Mice: reduced protection compared to prime alone & $(75)$ \\
\hline
\end{tabular}

The table illustrates some of the BCG boosters that have been tested against tuberculosis (TB) in animal models. Decreases in bacterial burdens were estimated from graphs if not specified and listed as follows for comparative purposes: up to 0.5 log decrease: slight; 0.5 to 1.0 log decrease: moderate; over 1.0 log decrease: strong. i.m., intramuscular; i.n., intranasal; s.c., subcutaneous.

secretion, enhanced maturation of phagosomes, and improved mycobacterial clearance by macrophages. Furthermore, zmp1deficient $\mathrm{Mtb}$ was attenuated compared to the $z m p 1^{+}$parental strain, showing reduced bacterial burdens in the lungs after aerosol challenge. A BCG mutant strain deficient in zmp1 also showed increased phagosome maturation and phagolysosome fusion $(147,148)$. This was demonstrated to facilitate antigen presentation and to increase mycobacteria-specific $\mathrm{CD}^{+}$and $\mathrm{CD}^{+} \mathrm{T}$-cell responses, emphasizing that phagolysosome fusion is important for generating immune responses to BCG antigens (148). Two zmp1-deficient strains, BCG Pasteur $\Delta z m p 1:: a p h$ and BCG Danish $\Delta z m p 1$, induced increased IFN- $\gamma^{+} \mathrm{CD} 4^{+}$T-cell responses in cattle compared to BCG (149). Efficacy testing in guinea pigs demonstrated that zmp1-deficient BCG strains were more protective than BCG, with BCG Pasteur SmR zmp1::aph and BCG Denmark $\Delta z m p 1$, further reducing lung bacterial loads compared to their parental BCG strains (103). Furthermore, the $\Delta z m p 1$ mutants showed increased safety in immunocompromised SCID mice compared to BCG.

\section{BOOSTING BCG WITH SUBUNIT VACCINES}

Originally, it was thought that subunit protein vaccines had the potential to replace BCG, but evaluation of an extensive number of subunit vaccine candidates in animal models has demonstrated that at best, these match the protection afforded by BCG (150-152). In general, a survey of the literature shows that protection afforded by subunit vaccines is not as effective as that induced by live attenuated mycobacterial strains. However, subunit vaccines can increase protective efficacy when administered as boosters to a BCG prime and, thus, have an important role to play in TB vaccination strategies. Furthermore, testing does not necessitate withholding the BCG vaccine, which has been shown to be partially effective. Most people are vaccinated against BCG in infancy, and protection wanes after approximately 20 years (19). Table 2 summarizes the results of preclinical efficacy testing of some of the subunit vaccines that have been tested as BCG boosters. In some cases, subunit vaccine boosters have been used with an rBCG prime. This is by no means an exhaustive list but serves to illustrate the type of subunit vaccines being tested. The majority of the subunit vaccine boosters that reduce bacterial burdens compared to BCG in mice or guinea pigs only reduce them slightly, but some have also shown beneficial effects on survival and lung pathology. The ability to induce high levels of cytokine-producing $\mathrm{CD}^{+}$and $\mathrm{CD} 8^{+} \mathrm{T}$ cells does not necessarily correlate with protection, as in some cases vaccine candidates were very immunogenic but did not reduce bacterial loads or pathology $(75,153)$.

\section{CONCLUSION}

Bacille Calmette-Guérin can contribute to the control of TB, being most effective in children and those not previously infected with Mtb or sensitized to environmental mycobacteria (17-19, 22). However, BCG fails to adequately protect those in high-risk environments, where the prevalence of $\mathrm{Mtb}$ is high and socioeconomic conditions are poor. A wide variety of rBCG strains and subunit vaccines have been tested in pre-clinical trials. Only one rBCG is now in clinical trials (VPM1002), while other vaccine candidates in clinical trials include inactivated whole cell vaccines, attenuated mycobacterial strains and subunit vaccine boosters focusing mostly on a narrow range of antigens (Ag85 family, ESAT-6) $(14,15)$. Head-to-head testing of vaccine candidates in pre-clinical models may be useful for identifying the most promising candidates worth moving forward to clinical trials (152). A number of studies have revealed that the immunogenicity parameters measured often do not translate to increased efficacy, and hence pre-clinical trials should always include Mtb challenge $(75,153)$. Statistical analysis should be performed comparing novel candidates against BCG, the current clinical vaccine with proven partial efficacy in humans. In summary, it seems likely that an improved vaccination regimen against TB can be achieved, but overcoming the current limits in protective efficacy will require novel approaches.

\section{AUTHOR CONTRIBUTIONS}

Both authors wrote the manuscript and approved it for publication.

\section{ACKNOWLEDGMENTS}

We thank Christian Goosman for transmission electron microscopy and Diane Schad for graphic design. We are grateful for the administrative support of Souraya Sibaei and Katja Grunow. This work was supported by The European Union's Seventh Framework Programme (EU FP7) ADITEC (HEALTH-F4-2011-280873), by the EU Horizon 2020 project TBVAC 2020 (grant no 643381), and the Bundesministerium für Bildung und Forschung (BMBF) project "Infect Control 2020" (grant no 03ZZ0806A) to SK. 


\section{REFERENCES}

1. WHO. Global Tuberculosis Report 2017. Geneva Switzerland: WHO Press (2017).

2. Houben RM, Dodd PJ. The global burden of latent tuberculosis infection: a re-estimation using mathematical modelling. PLoS Med (2016) 13(10):e1002152. doi:10.1371/journal.pmed.1002152

3. McShane H. Co-infection with HIV and TB: double trouble. Int J STD AIDS (2005) 16(2):95-100; quiz 1. doi:10.1258/0956462053057576

4. Wang JY, Lee MC, Shu CC, Lee CH, Lee LN, Chao KM, et al. Optimal duration of anti-TB treatment in patients with diabetes: nine or six months? Chest (2015) 147(2):520-8. doi:10.1378/chest.14-0918

5. Jacobson KR, Tierney DB, Jeon CY, Mitnick CD, Murray MB. Treatment outcomes among patients with extensively drug-resistant tuberculosis: systematic review and meta-analysis. Clin Infect Dis (2010) 51(1):6-14. doi: $10.1086 / 653115$

6. Narasimhan P, Wood J, Macintyre CR, Mathai D. Risk factors for tuberculosis. Pulm Med (2013) 2013:828939. doi:10.1155/2013/828939

7. Calmette A, Guérin C, Boquet A, Négre L. La vaccination préventive contre la tuberculose par le "BCG". Paris: Masson (1927). 1927 p.

8. Bekkering S, Blok BA, Joosten LA, Riksen NP, van Crevel R, Netea MG. In vitro experimental model of trained innate immunity in human primary monocytes. Clin Vaccine Immunol (2016) 23(12):926-33. doi:10.1128/CVI. 00349-16

9. Aaby P, Kollmann TR, Benn CS. Nonspecific effects of neonatal and infant vaccination: public-health, immunological and conceptual challenges. Nat Immunol (2014) 15(10):895-9. doi:10.1038/ni.2961

10. Kandasamy R, Voysey M, McQuaid F, de Nie K, Ryan R, Orr O, et al. Nonspecific immunological effects of selected routine childhood immunisations: systematic review. BMJ (2016) 355:i5225. doi:10.1136/bmj.i5225

11. Talbot EA, Perkins MD, Silva SF, Frothingham R. Disseminated bacille Calmette-Guerin disease after vaccination: case report and review. Clin Infect Dis (1997) 24(6):1139-46. doi:10.1086/513642

12. Kaufmann SH, Lange C, Rao M, Balaji KN, Lotze M, Schito M, et al. Progress in tuberculosis vaccine development and host-directed therapies - a state of the art review. Lancet Respir Med (2014) 2(4):301-20. doi:10.1016/S2213-2600 (14)70033-5

13. Gengenbacher M, Nieuwenhuizen NE, Kaufmann S. BCG - old workhorse, new skills. Curr Opin Immunol (2017) 47:8-16. doi:10.1016/j.coi.2017.06.007

14. Fletcher HA, Schrager L. TB vaccine development and the end TB strategy: importance and current status. Trans R Soc Trop Med Hyg (2016) 110(4):212-8. doi:10.1093/trstmh/trw016

15. Kaufmann SH, Weiner J, von Reyn CF. Novel approaches to tuberculosis vaccine development. Int J Infect Dis (2017) 56:263-7. doi:10.1016/j. ijid.2016.10.018

16. Rao M, Cadieux N, Fitzpatrick M, Reed S, Arsenian S, Valentini D, et al. Mycobacterium tuberculosis proteins involved in cell wall lipid biosynthesis improve BCG vaccine efficacy in a murine TB model. Int J Infect Dis (2017) 56:274-82. doi:10.1016/j.ijid.2017.01.024

17. Colditz GA, Brewer TF, Berkey CS, Wilson ME, Burdick E, Fineberg HV, et al. Efficacy of BCG vaccine in the prevention of tuberculosis. Meta-analysis of the published literature. JAMA (1994) 271(9):698-702. doi:10.1001/ jama.1994.03510330076038

18. Mangtani P, Abubakar I, Ariti C, Beynon R, Pimpin L, Fine PE, et al. Protection by BCG vaccine against tuberculosis: a systematic review of randomized controlled trials. Clin Infect Dis (2014) 58(4):470-80. doi:10.1093/ cid/cit790

19. Mangtani P, Nguipdop-Djomo P, Keogh RH, Trinder L, Smith PG, Fine PE, et al. Observational study to estimate the changes in the effectiveness of bacillus Calmette-Guerin (BCG) vaccination with time since vaccination for preventing tuberculosis in the UK. Health Technol Assess (2017) 21(39):1-54. doi:10.3310/hta21390

20. Roy A, Eisenhut M, Harris RJ, Rodrigues LC, Sridhar S, Habermann S, et al. Effect of BCG vaccination against Mycobacterium tuberculosis infection in children: systematic review and meta-analysis. BMJ (2014) 349:g4643. doi:10.1136/bmj.g4643

21. Nguipdop-Djomo P, HeldalE, Rodrigues LC, Abubakar I, Mangtani P. Duration of BCG protection against tuberculosis and change in effectiveness with time since vaccination in Norway: a retrospective population-based cohort study. Lancet Infect Dis (2016) 16(2):219-26. doi:10.1016/S1473-3099(15)00400-4

22. Rodrigues LC, Diwan VK, Wheeler JG. Protective effect of BCG against tuberculous meningitis and miliary tuberculosis: a meta-analysis. Int J Epidemiol (1993) 22(6):1154-8. doi:10.1093/ije/22.6.1154

23. Ritz N, Hanekom WA, Robins-Browne R, Britton WJ, Curtis N. Influence of BCG vaccine strain on the immune response and protection against tuberculosis. FEMS Microbiol Rev (2008) 32(5):821-41. doi:10.1111/j.1574-6976. 2008.00118.x

24. Pereira SM, Dantas OM, Ximenes R, Barreto ML. [BCG vaccine against tuberculosis: its protective effect and vaccination policies]. Rev Saude Publica (2007) 41(Suppl 1):59-66. doi:10.1590/S0034-89102007000800009

25. Abubakar I, Pimpin L, Ariti C, Beynon R, Mangtani P, Sterne JA, et al. Systematic review and meta-analysis of the current evidence on the duration of protection by bacillus Calmette-Guerin vaccination against tuberculosis. Health Technol Assess (2013) 17(37):1-372, v-vi. doi:10.3310/hta17370

26. Moliva JI, Turner J, Torrelles JB. Immune responses to bacillus CalmetteGuerin vaccination: why do they fail to protect against Mycobacterium tuberculosis? Front Immunol (2017) 8:407. doi:10.3389/fimmu.2017.00407

27. Fine PE. Variation in protection by BCG: implications of and for heterologous immunity. Lancet (1995) 346(8986):1339-45. doi:10.1016/S0140-6736 (95)92348-9

28. Yuen CM, Amanullah F, Dharmadhikari A, Nardell EA, Seddon JA, Vasilyeva I, et al. Turning off the tap: stopping tuberculosis transmission through active case-finding and prompt effective treatment. Lancet (2015) 386(10010):2334-43. doi:10.1016/S0140-6736(15)00322-0

29. Gupta S, Shenoy VP, Mukhopadhyay C, Bairy I, Muralidharan S. Role of risk factors and socio-economic status in pulmonary tuberculosis: a search for the root cause in patients in a tertiary care hospital, South India. Trop Med Int Health (2011) 16(1):74-8. doi:10.1111/j.1365-3156.2010.02676.x

30. Oxlade $\mathrm{O}$, Murray M. Tuberculosis and poverty: why are the poor at greater risk in India? PLoS One (2012) 7(11):e47533. doi:10.1371/journal.pone.0047533

31. de la Fuente J, Diez-Delgado I, Contreras M, Vicente J, Cabezas-Cruz A, Tobes R, et al. Comparative genomics of field isolates of Mycobacterium bovis and $M$. caprae provides evidence for possible correlates with bacterial viability and virulence. PLoS Negl Trop Dis (2015) 9(11):e0004232. doi:10.1371/journal. pntd.0004232

32. Waters WR, Palmer MV, Buddle BM, Vordermeier HM. Bovine tuberculosis vaccine research: historical perspectives and recent advances. Vaccine (2012) 30(16):2611-22. doi:10.1016/j.vaccine.2012.02.018

33. Buddle BM, Parlane NA, Keen DL, Aldwell FE, Pollock JM, Lightbody K, et al. Differentiation between Mycobacterium bovis BCG-vaccinated and $M$. bovis-infected cattle by using recombinant mycobacterial antigens. Clin Diagn Lab Immunol (1999) 6(1):1-5.

34. Whelan AO, Clifford D, Upadhyay B, Breadon EL, McNair J, Hewinson GR, et al. Development of a skin test for bovine tuberculosis for differentiating infected from vaccinated animals. J Clin Microbiol (2010) 48(9):3176-81. doi:10.1128/JCM.00420-10

35. Lopez-Valencia G, Renteria-Evangelista T, Williams Jde J, Licea-Navarro A, Mora-Valle Ade L, Medina-Basulto G. Field evaluation of the protective efficacy of Mycobacterium bovis BCG vaccine against bovine tuberculosis. Res Vet Sci (2010) 88(1):44-9. doi:10.1016/j.rvsc.2009.05.022

36. Ameni G, Vordermeier M, Aseffa A, Young DB, Hewinson RG. Field evaluation of the efficacy of Mycobacterium bovis bacillus Calmette-Guerin against bovine tuberculosis in neonatal calves in Ethiopia. Clin Vaccine Immunol (2010) 17(10):1533-8. doi:10.1128/CVI.00222-10

37. Sallusto F, Geginat J, Lanzavecchia A. Central memory and effector memory T cell subsets: function, generation, and maintenance. Annu Rev Immunol (2004) 22:745-63. doi:10.1146/annurev.immunol.22.012703.104702

38. Sakai S, Kauffman KD, Schenkel JM, McBerry CC, Mayer-Barber KD, Masopust D, et al. Cutting edge: control of Mycobacterium tuberculosis infection by a subset of lung parenchyma-homing CD4 T cells. J Immunol (2014) 192(7):2965-9. doi:10.4049/jimmunol.1400019

39. Sharpe S, White A, Sarfas C, Sibley L, Gleeson F, McIntyre A, et al. Alternative BCG delivery strategies improve protection against Mycobacterium tuberculosis in non-human primates: protection associated with mycobacterial antigen-specific CD4 effector memory T-cell populations. Tuberculosis (Edinb) (2016) 101:174-90. doi:10.1016/j.tube.2016.09.004 
40. Chen CY, Huang D, Wang RC, Shen L, Zeng G, Yao S, et al. A critical role for CD8 T cells in a nonhuman primate model of tuberculosis. PLoS Pathog (2009) 5(4):e1000392. doi:10.1371/journal.ppat.1000392

41. Lindenstrom T, Knudsen NP, Agger EM, Andersen P. Control of chronic Mycobacterium tuberculosis infection by CD4 KLRG1- IL-2-secreting central memory cells.J Immunol (2013) 190(12):6311-9. doi:10.4049/jimmunol.1300248

42. Vogelzang A, Perdomo C, Zedler U, Kuhlmann S, Hurwitz R, Gengenbacher $\mathrm{M}$, et al. Central memory CD4+ T cells are responsible for the recombinant bacillus Calmette-Guerin DeltaureC:hly vaccine's superior protection against tuberculosis. J Infect Dis (2014) 210(12):1928-37. doi:10.1093/infdis/jiu347

43. Perdomo C, Zedler U, Kuhl AA, Lozza L, Saikali P, Sander LE, et al. Mucosal BCG vaccination induces protective lung-resident memory $\mathrm{T}$ cell populations against tuberculosis. MBio (2016) 7(6):e1686-1616. doi:10.1128/ mBio.01686-16

44. Venkatasubramanian S, Cheekatla S, Paidipally P, Tripathi D, Welch E, Tvinnereim AR, et al. IL-21-dependent expansion of memory-like NK cells enhances protective immune responses against Mycobacterium tuberculosis. Mucosal Immunol (2017) 10(4):1031-42. doi:10.1038/mi.2016.105

45. Netea MG, van Crevel R. BCG-induced protection: effects on innate immune memory. Semin Immunol (2014) 26(6):512-7. doi:10.1016/j.smim.2014.09.006

46. Li H, Wang XX, Wang B, Fu L, Liu G, Lu Y, et al. Latently and uninfected healthcare workers exposed to TB make protective antibodies against Mycobacterium tuberculosis. Proc Natl Acad Sci U S A (2017) 114(19):5023-8. doi:10.1073/pnas.1611776114

47. Lu LL, Chung AW, Rosebrock TR, Ghebremichael M, Yu WH, Grace PS, et al. A functional role for antibodies in tuberculosis. Cell (2016) 167(2):433-43. e14. doi:10.1016/j.cell.2016.08.072

48. Achkar JM, Chan J, Casadevall A. B cells and antibodies in the defense against Mycobacterium tuberculosis infection. Immunol Rev (2015) 264(1):167-81. doi:10.1111/imr.12276

49. Dorhoi A, ReeceST, KaufmannSH. Forbetter or for worse: the immune response against Mycobacterium tuberculosis balances pathology and protection. Immunol Rev (2011) 240(1):235-51. doi:10.1111/j.1600-065X.2010.00994.X

50. Knaul JK, Jorg S, Oberbeck-Mueller D, Heinemann E, Scheuermann L, Brinkmann $\mathrm{V}$, et al. Lung-residing myeloid-derived suppressors display dual functionality in murine pulmonary tuberculosis. Am J Respir Crit Care Med (2014) 190(9):1053-66. doi:10.1164/rccm.201405-0828OC

51. Kleinnijenhuis J, Quintin J, Preijers F, Benn CS, Joosten LA, Jacobs C, et al. Long-lasting effects of BCG vaccination on both heterologous Th1/Th17 responses and innate trained immunity. J Innate Immun (2014) 6(2):152-8. doi: $10.1159 / 000355628$

52. Kaveh DA, Carmen Garcia-Pelayo M, Hogarth PJ. Persistent BCG bacilli perpetuate $\mathrm{CD} 4 \mathrm{~T}$ effector memory and optimal protection against tuberculosis. Vaccine (2014) 32(51):6911-8. doi:10.1016/j.vaccine.2014.10.041

53. Schaible UE, Winau F, Sieling PA, Fischer K, Collins HL, Hagens K, et al. Apoptosis facilitates antigen presentation to T lymphocytes through MHC-I and CD1 in tuberculosis. Nat Med (2003) 9(8):1039-46. doi:10.1038/nm906

54. Nandakumar S, Kannanganat S, Posey JE, Amara RR, Sable SB. Attrition of T-cell functions and simultaneous upregulation of inhibitory markers correspond with the waning of BCG-induced protection against tuberculosis in mice. PLoS One (2014) 9(11):e113951. doi:10.1371/journal.pone.0113951

55. Ottenhoff TH, Kaufmann SH. Vaccines against tuberculosis: where are we and where do we need to go? PLoS Pathog (2012) 8(5):e1002607. doi:10.1371/ journal.ppat.1002607

56. Orme IM. The Achilles heel of BCG. Tuberculosis (Edinb) (2010) 90(6):329-32. doi:10.1016/j.tube.2010.06.002

57. Henao-Tamayo MI, Ordway DJ, Irwin SM, Shang S, Shanley C, Orme IM. Phenotypic definition of effector and memory T-lymphocyte subsets in mice chronically infected with Mycobacterium tuberculosis. Clin Vaccine Immunol (2010) 17(4):618-25. doi:10.1128/CVI.00368-09

58. Kirman JR, Henao-Tamayo MI, Agger EM. The memory immune response to tuberculosis. Microbiol Spectr (2016) 4(6). doi:10.1128/microbiolspec. TBTB2-0009-2016

59. Barreto ML, Pereira SM, Ferreira AA. BCG vaccine: efficacy and indications for vaccination and revaccination. J Pediatr (Rio J) (2006) 82(3 Suppl):S45-54. doi:10.2223/JPED.1499

60. Simeone R, Bottai D, Brosch R. ESX/type VII secretion systems and their role in host-pathogen interaction. Curr Opin Microbiol (2009) 12(1):4-10. doi:10.1016/j.mib.2008.11.003
61. Velmurugan K, Chen B, Miller JL, Azogue S, Gurses S, Hsu T, et al. Mycobacterium tuberculosis nuoG is a virulence gene that inhibits apoptosis of infected host cells. PLoS Pathog (2007) 3(7):e110. doi:10.1371/journal. ppat.0030110

62. Reiley WW, Shafiani S, Wittmer ST, Tucker-Heard G, Moon JJ, Jenkins MK, et al. Distinct functions of antigen-specific CD4 T cells during murine Mycobacterium tuberculosis infection. Proc Natl Acad Sci U S A (2010) 107(45):19408-13. doi:10.1073/pnas.1006298107

63. Boer MC, van Meijgaarden KE, Goletti D, Vanini V, Prins C, Ottenhoff TH, et al. KLRG1 and PD-1 expression are increased on T-cells following tuberculosis-treatment and identify cells with different proliferative capacities in BCG-vaccinated adults. Tuberculosis (Edinb) (2016) 97:163-71. doi:10.1016/j. tube.2015.11.008

64. Jurado JO, Alvarez IB, Pasquinelli V, Martinez GJ, Quiroga MF, Abbate E, et al. Programmed death (PD)-1: PD-ligand 1/PD-ligand 2 pathway inhibits $\mathrm{T}$ cell effector functions during human tuberculosis. JImmunol (2008) 181(1):116-25. doi:10.4049/jimmunol.181.1.116

65. Khan N, Vidyarthi A, Amir M, Mushtaq K, Agrewala JN. T-cell exhaustion in tuberculosis: pitfalls and prospects. Crit Rev Microbiol (2017) 43(2):133-41. doi:10.1080/1040841X.2016.1185603

66. Carpenter SM, Yang JD, Lee J, Barreira-Silva P, Behar SM. Vaccine-elicited memory CD4+ T cell expansion is impaired in the lungs during tuberculosis. PLoS Pathog (2017) 13(11):e1006704. doi:10.1371/journal.ppat.1006704

67. Srivastava S, Ernst JD. Cell-to-cell transfer of M. tuberculosis antigens optimizes CD4 T cell priming. Cell Host Microbe (2014) 15(6):741-52. doi:10.1016/j.chom.2014.05.007

68. Griffiths KL, Ahmed M, Das S, Gopal R, Horne W, Connell TD, et al. Targeting dendritic cells to accelerate T-cell activation overcomes a bottleneck in tuberculosis vaccine efficacy. Nat Commun (2016) 7:13894. doi:10.1038/ ncomms 13894

69. Winau F, Weber S, Sad S, de Diego J, Hoops SL, Breiden B, et al. Apoptotic vesicles crossprime $\mathrm{CD} 8 \mathrm{~T}$ cells and protect against tuberculosis. Immunity (2006) 24(1):105-17. doi:10.1016/j.immuni.2005.12.001

70. Lindenstrom T, Woodworth J, Dietrich J, Aagaard C, Andersen P, Agger EM. Vaccine-induced th17 cells are maintained long-term postvaccination as a distinct and phenotypically stable memory subset. Infect Immun (2012) 80(10):3533-44. doi:10.1128/IAI.00550-12

71. Woodworth JS, Cohen SB, Moguche AO, Plumlee CR, Agger EM, Urdahl KB, et al. Subunit vaccine H56/CAF01 induces a population of circulating CD4 $\mathrm{T}$ cells that traffic into the Mycobacterium tuberculosis-infected lung. Mucosal Immunol (2017) 10(2):555-64. doi:10.1038/mi.2016.70

72. Barber DL. Vaccination for Mycobacterium tuberculosis infection: reprogramming CD4 T-cell homing into the lung. Mucosal Immunol (2017) 10(2):318-21. doi:10.1038/mi.2016.110

73. Pym AS, Brodin P, Brosch R, Huerre M, Cole ST. Loss of RD1 contributed to the attenuation of the live tuberculosis vaccines Mycobacterium bovis BCG and Mycobacterium microti. Mol Microbiol (2002) 46(3):709-17. doi:10.1046/j.1365-2958.2002.03237.x

74. Pym AS, Brodin P, Majlessi L, Brosch R, Demangel C, Williams A, et al. Recombinant BCG exporting ESAT-6 confers enhanced protection against tuberculosis. Nat Med (2003) 9(5):533-9. doi:10.1038/nm859

75. Dey B, Jain R, Khera A, Rao V, Dhar N, Gupta UD, et al. Boosting with a DNA vaccine expressing ESAT-6 (DNAE6) obliterates the protection imparted by recombinant BCG (rBCGE6) against aerosol Mycobacterium tuberculosis infection in guinea pigs. Vaccine (2009) 28(1):63-70. doi:10.1016/j.vaccine. 2009.09.121

76. Horwitz MA, Harth G. A new vaccine against tuberculosis affords greater survival after challenge than the current vaccine in the guinea pig model of pulmonary tuberculosis. Infect Immun (2003) 71(4):1672-9. doi:10.1128/ IAI.71.4.1672-1679.2003

77. Hoft DF, Blazevic A, Abate G, Hanekom WA, Kaplan G, Soler JH, et al. A new recombinant bacille Calmette-Guerin vaccine safely induces significantly enhanced tuberculosis-specific immunity in human volunteers. J Infect Dis (2008) 198(10):1491-501. doi:10.1086/592450

78. Tullius MV, Harth G, Maslesa-Galic S, Dillon BJ, Horwitz MA. A replication-limited recombinant Mycobacterium bovis BCG vaccine against tuberculosis designed for human immunodeficiency virus-positive persons is safer and more efficacious than BCG. Infect Immun (2008) 76(11):5200-14. doi:10.1128/IAI.00434-08 
79. Dai FY, Wang JF, Gong XL, Bao L. Immunogenicity and protective efficacy of recombinant bacille Calmette-Guerin strains expressing Mycobacterium antigens Ag85A, CFP10, ESAT-6, GM-CSF and IL-12p70. Hum Vaccin Immunother (2017) 13(6):1-8. doi:10.1080/21645515.2017.1279771

80. Yuan X, Teng X, Jing Y, Ma J, Tian M, Yu Q, et al. A live attenuated BCG vaccine overexpressing multistage antigens Ag85B and HspX provides superior protection against Mycobacterium tuberculosis infection. Appl Microbiol Biotechnol (2015) 99(24):10587-95. doi:10.1007/s00253-015-6962-x

81. Sali M, Di Sante G, Cascioferro A, Zumbo A, Nicolo C, Dona V, et al. Surface expression of MPT64 as a fusion with the PE domain of PE_PGRS33 enhances Mycobacterium bovis BCG protective activity against Mycobacterium tuberculosis in mice. Infect Immun (2010) 78(12):5202-13. doi:10.1128/IAI.00267-10

82. Bottai D, Frigui W, Clark S, Rayner E, Zelmer A, Andreu N, et al. Increased protective efficacy of recombinant BCG strains expressing virulence-neutral proteins of the ESX-1 secretion system. Vaccine (2015) 33(23):2710-8. doi:10.1016/j.vaccine.2015.03.083

83. Groschel MI, Sayes F, Shin SJ, Frigui W, Pawlik A, Orgeur M, et al. Recombinant BCG expressing ESX-1 of Mycobacterium marinum combines low virulence with cytosolic immune signaling and improved TB protection. Cell Rep (2017) 18(11):2752-65. doi:10.1016/j.celrep.2017.02.057

84. Murray PJ, Aldovini A, Young RA. Manipulation and potentiation of antimycobacterial immunity using recombinant bacille Calmette-Guerin strains that secrete cytokines. Proc Natl Acad Sci U S A (1996) 93(2):934-9. doi:10.1073/pnas.93.2.934

85. O’Donnell MA, Aldovini A, Duda RB, Yang H, Szilvasi A, Young RA, et al. Recombinant Mycobacterium bovis BCG secreting functional interleukin-2 enhances gamma interferon production by splenocytes. Infect Immun (1994) 62(6):2508-14.

86. Luo Y, Yamada H, Chen X, Ryan AA, EvanoffDP, Triccas JA, et al. Recombinant Mycobacterium bovis bacillus Calmette-Guerin (BCG) expressing mouse IL-18 augments Th1 immunity and macrophage cytotoxicity. Clin Exp Immunol (2004) 137(1):24-34. doi:10.1111/j.1365-2249.2004.02522.x

87. Biet F, Kremer L, Wolowczuk I, Delacre M, Locht C. Mycobacterium bovis BCG producing interleukin-18 increases antigen-specific gamma interferon production in mice. Infect Immun (2002) 70(12):6549-57. doi:10.1128/ IAI.70.12.6549-6557.2002

88. Young S, O'Donnell M, Lockhart E, Buddle B, Slobbe L, Luo Y, et al. Manipulation of immune responses to Mycobacterium bovis by vaccination with IL-2- and IL-18-secreting recombinant bacillus Calmette Guerin. ImmunolCellBiol(2002) 80(3):209-15.doi:10.1046/j.1440-1711.2002.01078.x

89. Moreira AL, Tsenova L, Murray PJ, Freeman S, Bergtold A, Chiriboga L, et al. Aerosol infection of mice with recombinant BCG secreting murine IFN-gamma partially reconstitutes local protective immunity. Microb Pathog (2000) 29(3):175-85. doi:10.1006/mpat.2000.0382

90. Tang C, Yamada H, Shibata K, Maeda N, Yoshida S, Wajjwalku W, et al. Efficacy of recombinant bacille Calmette-Guerin vaccine secreting interleukin-15/ antigen 85B fusion protein in providing protection against Mycobacterium tuberculosis. J Infect Dis (2008) 197(9):1263-74. doi:10.1086/586902

91. Shen H, Wang C, Yang E, Xu Y, Liu W, Yan J, et al. Novel recombinant BCG coexpressing Ag85B, ESAT-6 and mouse TNF-alpha induces significantly enhanced cellular immune and antibody responses in C57BL/6 mice. Microbiol Immunol (2010) 54(8):435-41. doi:10.1111/j.1348-0421.2010.00232.x

92. Xu Y, Zhu B, Wang Q, Chen J, Qie Y, Wang J, et al. Recombinant BCG coexpressing Ag85B, ESAT-6 and mouse-IFN-gamma confers effective protection against Mycobacterium tuberculosis in C57BL/6 mice. FEMS Immunol Med Microbiol (2007) 51(3):480-7. doi:10.1111/j.1574-695X.2007.00322.x

93. Wang Y, Yang C, He Y, Zhan X, Xu L. Iprl modified BCG as a novel vaccine induces stronger immunity than BCG against tuberculosis infection in mice. Mol Med Rep (2016) 14(2):1756-64. doi:10.3892/mmr.2016.5447

94. Ryan AA, Spratt JM, Britton WJ, Triccas JA. Secretion of functional monocyte chemotactic protein 3 by recombinant Mycobacterium bovis BCG attenuates vaccine virulence and maintains protective efficacy against $M$. tuberculosis infection. Infect Immun (2007) 75(1):523-6. doi:10.1128/IAI.00897-06

95. Grode L, Seiler P, Baumann S, Hess J, Brinkmann V, Nasser-Eddine A, et al. Increased vaccine efficacy against tuberculosis of recombinant Mycobacterium bovis bacille Calmette-Guerin mutants that secrete listeriolysin. J Clin Invest (2005) 115(9):2472-9. doi:10.1172/JCI24617

96. Gengenbacher M, Nieuwenhuizen N, Vogelzang A, Liu H, Kaiser P, Schuerer S, et al. Deletion of nuoG from the vaccine candidate Mycobacterium bovis BCG
DeltaureC::hly improves protection against tuberculosis. MBio (2016) 7(3):e00679-16. doi:10.1128/mBio.00679-16

97. Gengenbacher M, Kaiser P, Schuerer S, Lazar D, Kaufmann SH. Postexposure vaccination with the vaccine candidate bacillus Calmette-Guerin DeltaureC::hly induces superior protection in a mouse model of subclinical tuberculosis. Microbes Infect (2016) 18(5):364-8. doi:10.1016/j. micinf.2016.03.005

98. ReeceST, Nasser-Eddine A, Dietrich J, Stein M,Zedler U, Schommer-LeitnerS, et al. Improved long-term protection against Mycobacterium tuberculosis Beijing/W in mice after intra-dermal inoculation of recombinant BCG expressing latency associated antigens. Vaccine (2011) 29(47):8740-4. doi:10.1016/ j.vaccine.2011.07.144

99. Gengenbacher M, Vogelzang A, Schuerer S, Lazar D, Kaiser P, Kaufmann SH. Dietary pyridoxine controls efficacy of vitamin B6-auxotrophic tuberculosis vaccine bacillus Calmette-Guerin DeltaureC::hly Deltapdx1 in mice. MBio (2014) 5(3):e1262-1214. doi:10.1128/mBio.01262-14

100. Rao M, Vogelzang A, Kaiser P, Schuerer S, Kaufmann SH, Gengenbacher M. The tuberculosis vaccine candidate bacillus Calmette-Guerin DeltaureC::hly coexpressing human interleukin-7 or -18 enhances antigen-specific $\mathrm{T}$ cell responses in mice. PLoS One (2013) 8(11):e78966. doi:10.1371/journal. pone.0078966

101. Sun R, Skeiky YA, Izzo A, Dheenadhayalan V, Imam Z, Penn E, et al. Novel recombinant BCG expressing perfringolysin $\mathrm{O}$ and the over-expression of key immunodominant antigens; pre-clinical characterization, safety and protection against challenge with Mycobacterium tuberculosis. Vaccine (2009) 27(33):4412-23. doi:10.1016/j.vaccine.2009.05.048

102. Nascimento IP, Rodriguez D, Santos CC, Amaral EP, Rofatto HK, JunqueiraKipnis AP, et al. Recombinant BCG expressing LTAK63 adjuvant induces superior protection against Mycobacterium tuberculosis. Sci Rep (2017) 7(1):2109. doi:10.1038/s41598-017-02003-9

103. Sander P, Clark S, Petrera A, Vilaplana C, Meuli M, Selchow P, et al. Deletion of zmp1 improves Mycobacterium bovis BCG-mediated protection in a guinea pig model of tuberculosis. Vaccine (2015) 33(11):1353-9. doi:10.1016/j. vaccine.2015.01.058

104. Mahairas GG, Sabo PJ, Hickey MJ, Singh DC, Stover CK. Molecular analysis of genetic differences between Mycobacterium bovis BCG and virulent M. bovis. J Bacteriol (1996) 178(5):1274-82. doi:10.1128/jb.178.5.1274-1282.1996

105. Parkash O, Singh BP, Pai M. Regions of differences encoded antigens as targets for immunodiagnosis of tuberculosis in humans. Scand J Immunol (2009) 70(4):345-57. doi:10.1111/j.1365-3083.2009.02312.x

106. Behr MA, Wilson MA, Gill WP, Salamon H, Schoolnik GK, Rane S, et al. Comparative genomics of BCG vaccines by whole-genome DNA microarray. Science (1999) 284(5419):1520-3. doi:10.1126/science.284.5419.1520

107. Lewis KN, Liao R, Guinn KM, Hickey MJ, Smith S, Behr MA, et al. Deletion of RD1 from Mycobacterium tuberculosis mimics bacille Calmette-Guerin attenuation. J Infect Dis (2003) 187(1):117-23. doi:10.1086/345862

108. Brodin P, Rosenkrands I, Andersen P, Cole ST, Brosch R. ESAT-6 proteins: protective antigens and virulence factors? Trends Microbiol (2004) 12(11):500-8. doi:10.1016/j.tim.2004.09.007

109. Roche PW, Winter N, Triccas JA, Feng CG, Britton WJ. Expression of Mycobacterium tuberculosis MPT64 in recombinant Myco. smegmatis: purification, immunogenicity and application to skin tests for tuberculosis. Clin Exp Immunol (1996) 103(2):226-32. doi:10.1046/j.1365-2249.1996. d01-613.x

110. Brandt L, Skeiky YA, Alderson MR, Lobet Y, Dalemans W, Turner OC, et al. The protective effect of the Mycobacterium bovis BCG vaccine is increased by coadministration with the Mycobacterium tuberculosis 72-kilodalton fusion polyprotein Mtb72F in M. tuberculosis-infected guinea pigs. Infect Immun (2004) 72(11):6622-32. doi:10.1128/IAI.72.11.6622-6632.2004

111. Kupz A, Zedler U, Staber M, Perdomo C, Dorhoi A, Brosch R, et al. ESAT6-dependent cytosolic pattern recognition drives noncognate tuberculosis control in vivo. J Clin Invest (2016) 126(6):2109-22. doi:10.1172/jci84978

112. Aguilo N, Gonzalo-Asensio J, Alvarez-Arguedas S, Marinova D, Gomez AB, Uranga S, et al. Reactogenicity to major tuberculosis antigens absent in BCG is linked to improved protection against Mycobacterium tuberculosis. Nat Commun (2017) 8:16085. doi:10.1038/ncomms16085

113. Huygen $\mathrm{K}$. The immunodominant T-cell epitopes of the mycolyl-transferases of the antigen 85 complex of M. tuberculosis. Front Immunol (2014) 5:321. doi:10.3389/fimmu.2014.00321 
114. Groschel MI, Sayes F, Simeone R, Majlessi L, Brosch R. ESX secretion systems: mycobacterial evolution to counter host immunity. Nat Rev Microbiol (2016) 14(11):677-91. doi:10.1038/nrmicro.2016.131

115. Zheng YQ, Naguib YW, Dong Y, Shi YC, Bou S, Cui Z. Applications of bacillus Calmette-Guerin and recombinant bacillus Calmette-Guerin in vaccine development and tumor immunotherapy. Expert Rev Vaccines (2015) 14(9):1255-75.

116. Luo Y, Henning J, O’Donnell MA. Th1 cytokine-secreting recombinant Mycobacterium bovis bacillus Calmette-Guerin and prospective use in immunotherapy of bladder cancer. Clin Dev Immunol (2011) 2011:728930. doi: $10.1155 / 2011 / 728930$

117. Pan H, Yan BS, Rojas M, Shebzukhov YV, Zhou H, Kobzik L, et al. Iprl gene mediates innate immunity to tuberculosis. Nature (2005) 434(7034):767-72. doi: $10.1038 /$ nature03419

118. Kaufmann SH, Cotton MF, Eisele B, Gengenbacher M, Grode L, Hesseling AC, et al. The BCG replacement vaccine VPM1002: from drawing board to clinical trial. Expert Rev Vaccines (2014) 13(5):619-30. doi:10.1586/147605 84.2014.905746

119. Nieuwenhuizen NE, Kulkarni PS, Shaligram U, Cotton MF, Rentsch CA, Eisele B, et al. The recombinant bacille Calmette-Guerin vaccine VPM1002: ready for clinical efficacy testing. Front Immunol (2017) 8:1147. doi:10.3389/ fimmu.2017.01147

120. Sendide K, Deghmane AE, Reyrat JM, Talal A, Hmama Z. Mycobacterium bovis BCG urease attenuates major histocompatibility complex class II trafficking to the macrophage cell surface. Infect Immun (2004) 72(7):4200-9. doi:10.1128/IAI.72.7.4200-4209.2004

121. Clemens DL, Lee BY, Horwitz MA. Purification, characterization, and genetic analysis of Mycobacterium tuberculosis urease, a potentially critical determinant of host-pathogen interaction. J Bacteriol (1995) 177(19):5644-52. doi:10.1128/jb.177.19.5644-5652.1995

122. Lin W, Mathys V, Ang EL, Koh VH, Martinez Gomez JM, Ang ML, et al. Urease activity represents an alternative pathway for Mycobacterium tuberculosis nitrogen metabolism. Infect Immun (2012) 80(8):2771-9. doi:10.1128/ IAI.06195-11

123. Hamon MA, Ribet D, Stavru F, Cossart P. Listeriolysin O: the Swiss army knife of Listeria. Trends Microbiol (2012) 20(8):360-8. doi:10.1016/j.tim. 2012.04.006

124. Saiga H, Nieuwenhuizen N, Gengenbacher M, Koehler AB, Schuerer S, Moura-Alves $\mathrm{P}$, et al. The recombinant BCG DeltaureC::hly vaccine targets the AIM2 inflammasome to induce autophagy and inflammation. J Infect Dis (2015) 211(11):1831-41. doi:10.1093/infdis/jiu675

125. Farinacci M, Weber S, Kaufmann SH. The recombinant tuberculosis vaccine rBCG DeltaureC::hly(+) induces apoptotic vesicles for improved priming of CD4(+) and CD8(+) T cells. Vaccine (2012) 30(52):7608-14. doi:10.1016/j. vaccine.2012.10.031

126. Fletcher HA. Sleeping beauty and the story of the bacille Calmette-Guerin vaccine. MBio (2016) 7(4):e1370-1316. doi:10.1128/mBio.01370-16

127. Miller JL, Velmurugan K, Cowan MJ, Briken V. The type I NADH dehydrogenase of Mycobacterium tuberculosis counters phagosomal NOX2 activity to inhibit TNF-alpha-mediated host cell apoptosis. PLoS Pathog (2010) 6(4):e1000864. doi:10.1371/journal.ppat.1000864

128. Schneider BE, Korbel D, Hagens K, Koch M, Raupach B, Enders J, et al. A role for IL-18 in protective immunity against Mycobacterium tuberculosis. Eur J Immunol (2010) 40(2):396-405. doi:10.1002/eji.200939583

129. Netea MG, Azam T, Lewis EC, Joosten LA, Wang M, Langenberg D, et al. Mycobacterium tuberculosis induces interleukin-32 production through a caspase-1/IL-18/interferon-gamma-dependent mechanism. PLoS Med (2006) 3(8):e277. doi:10.1371/journal.pmed.0030277

130. Maeurer MJ, Trinder P, Hommel G, Walter W, Freitag K, Atkins D, et al. Interleukin-7 or interleukin-15 enhances survival of Mycobacterium tuberculosis-infected mice. Infect Immun (2000) 68(5):2962-70. doi:10.1128/ IAI.68.5.2962-2970.2000

131. Mackall CL, Fry TJ, Gress RE. Harnessing the biology of IL-7 for therapeutic application. Nat Rev Immunol (2011) 11(5):330-42. doi:10.1038/nri2970

132. Singh V, Gowthaman U, Jain S, Parihar P, Banskar S, Gupta P, et al. Coadministration of interleukins 7 and 15 with bacille Calmette-Guerin mounts enduring T cell memory response against Mycobacterium tuberculosis. J Infect Dis (2010) 202(3):480-9. doi:10.1086/653827

133. Gracie JA, Robertson SE, McInnes IB. Interleukin-18. J Leukoc Biol (2003) 73(2):213-24. doi:10.1189/jlb.0602313
134. Sugawara I, Yamada H, Kaneko H, Mizuno S, Takeda K, Akira S. Role of interleukin-18 (IL-18) in mycobacterial infection in IL-18-gene-disrupted mice. Infect Immun (1999) 67(5):2585-9.

135. Shimada Y, Maruya M, Iwashita S, Ohno-Iwashita Y. The C-terminal domain of perfringolysin $\mathrm{O}$ is an essential cholesterol-binding unit targeting to cholesterolrich microdomains. Eur J Biochem (2002) 269(24):6195-203. doi:10.1046/ j.1432-1033.2002.03338.x

136. Nelson LD, Johnson AE, London E. How interaction of perfringolysin $\mathrm{O}$ with membranes is controlled by sterol structure, lipid structure, and physiological low $\mathrm{pH}$ : insights into the origin of perfringolysin O-lipid raft interaction. J Biol Chem (2008) 283(8):4632-42. doi:10.1074/jbc.M709483200

137. Hoft DF, Blazevic A, Selimovic A, Turan A, Tennant J, Abate G, et al. Safety and immunogenicity of the recombinant BCG vaccine AERAS- 422 in healthy BCG-naive adults: a randomized, active-controlled, first-in-human phase 1 trial. EBioMedicine (2016) 7:278-86. doi:10.1016/j.ebiom.2016.04.010

138. Pizza M, Giuliani MM, Fontana MR, Monaci E, Douce G, Dougan G, et al. Mucosal vaccines: non toxic derivatives of LT and CT as mucosal adjuvants. Vaccine (2001) 19(17-19):2534-41. doi:10.1016/S0264-410X(00)00553-3

139. Biet F, Kremer L, Wolowczuk I, Delacre M, Locht C. Immune response induced by recombinant Mycobacterium bovis BCG producing the cholera toxin B subunit. Infect Immun (2003) 71(5):2933-7. doi:10.1128/ IAI.71.5.2933-2937.2003

140. Marinaro M, Riccomi A, Rappuoli R, Pizza M, Fiorelli V, Tripiciano A, et al. Mucosal delivery of the human immunodeficiency virus-1 Tat protein in mice elicits systemic neutralizing antibodies, cytotoxic T lymphocytes and mucosal IgA. Vaccine (2003) 21(25-26):3972-81. doi:10.1016/S0264-410X (03)00295-0

141. Dietrich J, Andersen C, Rappuoli R, Doherty TM, Jensen CG, Andersen P. Mucosal administration of Ag85B-ESAT-6 protects against infection with Mycobacterium tuberculosis and boosts prior bacillus Calmette-Guerin immunity. J Immunol (2006) 177(9):6353-60. doi:10.4049/jimmunol.177.9.6353

142. Badell E, Nicolle F, Clark S, Majlessi L, Boudou F, Martino A, et al. Protection against tuberculosis induced by oral prime with Mycobacterium bovis BCG and intranasal subunit boost based on the vaccine candidate Ag85B-ESAT-6 does not correlate with circulating IFN-gamma producing T-cells. Vaccine (2009) 27(1):28-37. doi:10.1016/j.vaccine.2008.10.034

143. Barnett SW, Srivastava IK, Kan E, Zhou F, Goodsell A, Cristillo AD, et al. Protection of macaques against vaginal SHIV challenge by systemic or mucosal and systemic vaccinations with HIV-envelope. AIDS (2008) 22(3):339-48. doi:10.1097/QAD.0b013e3282f3ca57

144. Peppoloni S, Ruggiero P, Contorni M, Morandi M, Pizza M, Rappuoli R, et al. Mutants of the Escherichia coli heat-labile enterotoxin as safe and strong adjuvants for intranasal delivery of vaccines. Expert Rev Vaccines (2003) 2(2):285-93. doi:10.1586/14760584.2.2.285

145. Lewis DJ, Huo Z, Barnett S, Kromann I, Giemza R, Galiza E, et al. Transient facial nerve paralysis (Bell's palsy) following intranasal delivery of a genetically detoxified mutant of Escherichia coli heat labile toxin. PLoS One (2009) 4(9):e6999. doi:10.1371/journal.pone.0006999

146. Mutsch M, Zhou W, Rhodes P, Bopp M, Chen RT, Linder T, et al. Use of the inactivated intranasal influenza vaccine and the risk of Bell's palsy in Switzerland. N Engl J Med (2004) 350(9):896-903. doi:10.1056/NEJMoa030595

147. Master SS, Rampini SK, Davis AS, Keller C, Ehlers S, Springer B, et al. Mycobacterium tuberculosis prevents inflammasome activation. Cell Host Microbe (2008) 3(4):224-32. doi:10.1016/j.chom.2008.03.003

148. Johansen P, Fettelschoss A, Amstutz B, Selchow P, Waeckerle-Men Y, Keller P, et al. Relief from Zmp1-mediated arrest of phagosome maturation is associated with facilitated presentation and enhanced immunogenicity of mycobacterial antigens. Clin Vaccine Immunol (2011) 18(6):907-13. doi:10.1128/ CVI.00015-11

149. Khatri B, Whelan A, Clifford D, Petrera A, Sander P, Vordermeier HM. BCG Deltazmpl vaccine induces enhanced antigen specific immune responses in cattle. Vaccine (2014) 32(7):779-84. doi:10.1016/j.vaccine.2013.12.055

150. Dalmia N, Ramsay AJ. Prime-boost approaches to tuberculosis vaccine development. Expert Rev Vaccines (2012) 11(10):1221-33. doi:10.1586/erv.12.94

151. Choi HG, Choi S, Back YW, Paik S, Park HS, Kim WS, et al. Rv2299c, a novel dendritic cell-activating antigen of Mycobacterium tuberculosis, fusedESAT-6 subunit vaccine confers improved and durable protection against the hypervirulent strain HN878 in mice. Oncotarget (2017) 8(12):19947-67. doi:10.18632/oncotarget.15256 
152. Williams A, Hatch GJ, Clark SO, Gooch KE, Hatch KA, Hall GA, et al. Evaluation of vaccines in the EU TB vaccine cluster using a guinea pig aerosol infection model of tuberculosis. Tuberculosis (Edinb) (2005) 85(1-2):29-38. doi:10.1016/j.tube.2004.09.009

153. Stylianou E, Griffiths KL, Poyntz HC, Harrington-Kandt R, Dicks MD, Stockdale L, et al. Improvement of BCG protective efficacy with a novel chimpanzee adenovirus and a modified vaccinia Ankara virus both expressing Ag85A. Vaccine (2015) 33(48):6800-8. doi:10.1016/j.vaccine.2015.10.017

154. Ahmed M, Smith DM, Hamouda T, Rangel-Moreno J, Fattom A, Khader SA. A novel nanoemulsion vaccine induces mucosal interleukin-17 responses and confers protection upon Mycobacterium tuberculosis challenge in mice. Vaccine (2017) 35(37):4983-9. doi:10.1016/j.vaccine.2017.07.073

155. Aagaard C, Hoang T, Dietrich J, Cardona PJ, Izzo A, Dolganov G, et al. A multistage tuberculosis vaccine that confers efficient protection before and after exposure. Nat Med (2011) 17(2):189-94. doi:10.1038/nm.2285

156. Skeiky YA, Dietrich J, Lasco TM, Stagliano K, Dheenadhayalan V, Goetz MA, et al. Non-clinical efficacy and safety of HyVac4:IC31 vaccine administered in a BCG prime-boost regimen. Vaccine (2010) 28(4):1084-93. doi:10.1016/j. vaccine.2009.10.114

157. Billeskov R, Elvang TT, Andersen PL, Dietrich J. The HyVac4 subunit vaccine efficiently boosts BCG-primed anti-mycobacterial protective immunity. PLoS One (2012) 7(6):e39909. doi:10.1371/journal.pone.0039909

158. Lin PL, Dietrich J, Tan E, Abalos RM, Burgos J, Bigbee C, et al. The multistage vaccine $\mathrm{H} 56$ boosts the effects of BCG to protect cynomolgus macaques against active tuberculosis and reactivation of latent Mycobacterium tuberculosis infection. J Clin Invest (2012) 122(1):303-14. doi:10.1172/JCI46252

159. Bertholet S, Ireton GC, Ordway DJ, Windish HP, Pine SO, Kahn M, et al. A defined tuberculosis vaccine candidate boosts BCG and protects against multidrug-resistant Mycobacterium tuberculosis. Sci Transl Med (2010) 2(53):53ra74. doi:10.1126/scitranslmed.3001094

160. Ma J, Teng X, Wang X, Fan X, Wu Y, Tian M, et al. A multistage subunit vaccine effectively protects mice against primary progressive tuberculosis, latency and reactivation. EBioMedicine (2017) 22:143-54. doi:10.1016/j. ebiom.2017.07.005

161. Lahey T, Laddy D, Hill K, Schaeffer J, Hogg A, Keeble J, et al. Immunogenicity and protective efficacy of the DAR-901 booster vaccine in a murine model of tuberculosis. PLoS One (2016) 11(12):e0168521. doi:10.1371/journal. pone. 0168521

162. Santosuosso M, McCormick S, Zhang X, Zganiacz A, Xing Z. Intranasal boosting with an adenovirus-vectored vaccine markedly enhances protection by parenteral Mycobacterium bovis BCG immunization against pulmonary tuberculosis. Infect Immun (2006) 74(8):4634-43. doi:10.1128/IAI.00517-06

163. Jia Q, Dillon BJ, Maslesa-Galic S, Horwitz MA. Listeria-vectored vaccine expressing the Mycobacterium tuberculosis $30 \mathrm{kDa}$ major secretory protein via the constitutively active prfA* regulon boosts BCG efficacy against tuberculosis. Infect Immun (2017) 85(9):e00245-17. doi:10.1128/IAI.00245-17

164. Xin Q, Niu H, Li Z, Zhang G, Hu L, Wang B, et al. Subunit vaccine consisting of multi-stage antigens has high protective efficacy against Mycobacterium tuberculosis infection in mice. PLoS One (2013) 8(8):e72745. doi:10.1371/ journal.pone.0072745

165. Cervantes-Villagrana AR, Hernandez-Pando R, Biragyn A, CastanedaDelgado J, Bodogai M, Martinez-Fierro M, et al. Prime-boost BCG vaccination with DNA vaccines based in beta-defensin-2 and mycobacterial antigens ESAT6 or Ag85B improve protection in a tuberculosis experimental model. Vaccine (2013) 31(4):676-84. doi:10.1016/j.vaccine.2012.11.042

166. Hu Z, Wong KW, Zhao HM, Wen HL, Ji P, Ma H, et al. Sendai virus mucosal vaccination establishes lung-resident memory CD8 T cell immunity and boosts BCG-primed protection against TB in mice. Mol Ther (2017) 25(5):1222-33. doi:10.1016/j.ymthe.2017.02.018

167. Saqib M, Khatri R, Singh B, Gupta A, Kumar A, Bhaskar S. Mycobacterium indicus pranii as a booster vaccine enhances BCG induced immunity and confers higher protection in animal models of tuberculosis. Tuberculosis (Edinb) (2016) 101:164-73. doi:10.1016/j.tube.2016.10.002

168. Tchilian EZ, Desel C, Forbes EK, Bandermann S, Sander CR, Hill AV, et al. Immunogenicity and protective efficacy of prime-boost regimens with recombinant (delta)ureC hly+ Mycobacterium bovis BCG and modified vaccinia virus ankara expressing $M$. tuberculosis antigen $85 \mathrm{~A}$ against murine tuberculosis. Infect Immun (2009) 77(2):622-31. doi:10.1128/ IAI.00685-08

169. Goonetilleke NP, McShane H, Hannan CM, Anderson RJ, Brookes RH, Hill AV. Enhanced immunogenicity and protective efficacy against Mycobacterium tuberculosis of bacille Calmette-Guerin vaccine using mucosal administration and boosting with a recombinant modified vaccinia virus Ankara. J Immunol (2003) 171(3):1602-9. doi:10.4049/jimmunol.171.3.1602

170. Yang E, Gu J, Wang F, Wang H, Shen H, Chen ZW. Recombinant BCG prime and PPE protein boost provides potent protection against acute Mycobacterium tuberculosis infection in mice. Microb Pathog (2016) 93:1-7. doi:10.1016/j.micpath.2016.01.006

Conflict of Interest Statement: SK is co-inventor/patent holder of VPM1002. NN has no conflicts of interest.

Copyright (c) 2018 Nieuwenhuizen and Kaufmann. This is an open-access article distributed under the terms of the Creative Commons Attribution License (CC $B Y)$. The use, distribution or reproduction in other forums is permitted, provided the original author(s) and the copyright owner are credited and that the original publication in this journal is cited, in accordance with accepted academic practice. No use, distribution or reproduction is permitted which does not comply with these terms. 